$\mathrm{F} 1219.3$

. A35

$\$ 73$

Steffen, Max

Uber die Landwirtschaft bei den Altamerikanischen Kulturvölkern 





\section{DIE AZTEKEN.}

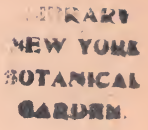

\section{, I. \\ Quellen.}

Die Quellen, welche der folgenden Untersuchung zu Grunde liegen, lassen sich zweckmässig in vier Klassen einteilen:

I. Die erste Klasse bilden die Werke derjenigen Schriftsteller, welche entweder bei der Entdeckung und Eroberung beteiligt oder doch so bald darauf im Lande selbst waren, dass sie noch Leute kennen lernen konnten, welche das Reich des Montezuma in seiner ganzen Grösse gesehen hatten und bei denen alle Traditionen noch lebendig waren. Von derartigen Werken sind folgende benutzt worden:

1. Hernan CoRtez hat uns Cuatro Cartas al emperador Carlo V hinterlassen, von denen die erste 1522 in Sevilla gedruckt wurde. Wir dürfen seine Berichte wohl als wahrheitsgetreu ansehen, da seine zahlreichen Feinde bei Hofe, im Falle er unwahres berichtet hätte, sich das gewiss zu Nutze gemacht haben würden.

2. Bernal Diaz del Castillo schrieb 1568 eine Historia verdadera de la conquista de la Nueva España, die 1632 in - Madrid veröffentlicht wurde. Wichtig ist, dass er Augenzeuge Mlles dessen war, was er berichtet. Seine Absicht bei NiederTschrift der Historia verdadera war, sich und seine WaffengeL Jährten, die echten Conquistadoren, gegen die Angriffe einiger -Geschichtsschreiber zu verteidigen, die gar nicht Augenzeugen çder Eroberung gewesen waren. Die Erzählung ihrer Helden- 
thaten auf dem Eroberungszuge ist ihm zunächst das wichtigste, nur vereinzelt und zufällig nimmt er auf die Kulturzustände Bezug. Er wollte ja nicht als Autorität in Betreff der Altertümer des Landes angesehen werden. Darum aber haben seine Angaben um so grösseren Wert. Dabei schrieb er zu einer Zeit, wo noch viele lebten, die ihm widersprechen konnten, wenn er Unwahrheiten zu Tage brachte. Das beste Zeugnis für seine Treue und Wahrhaftigkeit ist wohl, dass seine Historia verdadera von Seiten der gleichzeitigen wie nachfolgenden Geschichtsschreiber niemals eine wesentliche Anfechtung erfahren hat. Wenn er auch bei seiner Unwissenheit sich vieles nicht zu erklären wusste und manches vergessen hatte, als er über 40. Jahre nach der Eroberung seine Geschichte verfasste, so müssen wir ihm für seine flüchtigen und unvollkommenen Beobachtungen doch dankbar sein und dürfen sie bei einer Behandlung des Kulturzustandes im alten Mejico durchaus nicht unbenutzt lassen.

3. Einer von den Conquistadoren, dessen Name nicht bekannt ist, hat uns einen kurzen Bericht hinterlassen, worin er erzählt, was er in Mejico über Tempel, Wohnungen, Kleidung, Waffen, Essen etc. beobachtete. Er ist abgedruckt bei Ramusio, Navigacioni e viaggi Bd. III.

4. Girolamo Benzont wurde in Mailand um 1519 geboren und ging, wie wir von ihm selbst zu Anfang seines Werkes erfahren, im Jahre 1541 nach Amerika. Er hielt sich hier 14 Jahre auf, zuerst auf den grossen Antillen, dann in Panama, Costa Rica, Nicaragua, Guatemala und schliesslich in Peru. Nach seiner Rückkehr in die Heimat veröffentlichte er $1565 \mathrm{zu}$ Venedig seine Historia del Mondo Nuovo, die er dem Papst Pius IV. zueignete. Sie wurde bald ins Lateinische, Griechische, Deutsche und Flämische übersetzt. Seine Erzählung ist zwar schlecht geschrieben, aber streng wahrheitsgetreu in allen den Sachen, bei denen er persönlich beteiligt war.

5. Bernardino SaHagun, ein Franziskaner aus Spanien, brachte 60 Jahre in Mejico mit dem Unterrichten der Eingeborenen $\mathrm{zu}$, wobei er gewiss viele Beobachtungen machen konnte. Gestorben ist er am 23. Oktober 1590. Er verfasste 
eine Historia general de las cosas de la Nueva España, in der namentlich die religiösen Gebräuche behandelt sind ${ }^{1}$ ).

6. Alonzo DE ZURITA verbrachte 19 Jahre in Amerika und zwar nacheinander als Mitglied der Audiencias von NeuGranada, Guatemala und Mejico. Er ging dann nach Spanien zurück, wo er wohl gestorben ist. Wahrscheinlich fiel sein Aufenthalt in Amerika in die Jahre 1540-1560 und gegen das Ende dieser Zeit hat er jedenfalls auch seimen Bericht über die verschiedenen Klassen der Häuptlinge Neuspaniens verfasst ${ }^{2}$ ). Er enthält die Antworten auf die Fragen, welche der König in einem Erlass über die Unterthänigkeits- und Tributverhältnisse der Eingeborenen gestellt hatte, und als solchen dürfen wir ihnen genügenden Glauben beimessen.

7. Carta de D. Martin CoRtés, Segundo Marqués del Valle, al Rey D. Felipe II, sobre los repartimientos y clases de tierras de Nueva España ist datirt vom 10. Oktober 1563. Sie ist abgedruckt in der Coleccion de Documentos inéditos relativos al descubrimiento, conquista y organizacion de las antiguas posesiones españoles en América y Oceanra, sacados de los archivos del Reino, y muy especialmente del de In$\left.\operatorname{dias}^{3}\right)$, Bd. 4.

8. Relacion de la Provincia de Meztitlan, hecha por Gabriel De Chaves, Alcalde Mayor de esta provincia por S. M., de órden del Virey de Nueva-España, ist den 1. Oktober 1569 unterzeichnet und in demselben Bande wie die vorhergehende abgedruckt.

9. Juan Suarez de Peralta, dessen Geburt in die Zeit von 1535 bis 1540 fällt, verfasste einen Tratado del descubrimiento de las Indias y su conquista (wohl in den 80ger Jahren des 16. Jahrh.). Über den Kulturzustand des Landes

1) Eine eingehendere Kritik s. bei Prescott, Hist. of the conquest of Mexico, London 1843. Bd. 1. S. 78. 2) A. de Zurita, Rapport sur les différentes classes de chefs de la Nouvelle Espagne, publ. p. TernauxCompans. Paris 1840. S. X. ${ }^{3}$ ) Später nur als "Doc. inéd. de Indias" citirt, zum Unterschiede von den Doc. inéd. para la hist. de España. Näheres über die Berichte s. bei Peru (Quellen 1. Kl. No. 10). 
giebt er fast gar keinen Aufschluss. Veröffentlicht ist die Schrift in Justo Zaragoza, Noticias Históricas, Madrid 1878.

10. JoSEPH DE Acosta, ein spanischer Jesuit, wurde 1539 geboren, ging 1571 nach Amerika, wo er zweiter Provinzial von Peru wurde, verliess aber 1588 das Land und starb 1600 als Rektor zu Salamanca. Im Jahre 1590 veröffentlichte er zu Sevilla eine Historia natural y moral de las Indias, deren Angaben uns im allgemeinen ganz wertvoll sind. Für Mejico kommen sie wenig in Betracht und sind auch zum grössten Teil wohl von fremder Hand.

11. Alvarado Tezozomoc stammte von den Königen von Atzaputzalco ab. Der einzige Autor, der seiner Erwähnung thut, ist Veytia in seiner Historia antigua de Mexico (Mexico 1836). Sein Werk, die Crónica mexicana, schrieb er ungefähr 1598, so dass er in seiner Jugend noch mit Leuten zusammengekommen sein wird, die Montezumas Reich in seiner Blüte gesehen hatten ${ }^{1}$ ).

12. Fern. de Alva Ixthilxochitl war der Sohn eines Spaniers und einer Indianerin. Um 1600 schrieb er eine Historia de los Chichimecos, die indessen über den Kulturzustand äusserst wenig bringt. Er hat die Geschichtswerke der spanischen Chronisten gelesen und wirft ihnen, so vor allem dem Gomara, zahlreiche Irrtümer vor.

13. JUan dE ToRquemada veröffentlichte $1614 \mathrm{zu}$ Madrid die Libros rituales y Monarquia indiana, ein Werk, das zum grössten Teil die Geschichte Mejicos vor der Eroberung behandelt. Er lebte in Mejico von seiner Jugend an bis zu seinem Tode. Da er mehr als 50 Jahre mit den Eingeborenen verkehrte und ihrer Sprache mächtig war, so dürfen wir sein Werk, an dem er 20 Jahre schrieb, wohl als gute Quelle betrachten, wenn er gleich der Zeit nach von der Conquistadorenepoche schon weit entfernt und in dieser Hinsicht kaum noch der ersten Klasse zuzuzählen ist ${ }^{2}$ ).

1) Tezozomoc, Histoire du Mexique, trad. par Ternaux-Compans, Paris 1853. Vorrede. 2) Vgl. die Kritik bei Prescott, a. a. O. Bd. 1. S. 47.1 
14. Ritos antiguos, sacrificios é idolatrias de los Indios de la Nueva España y de su conversacion á la Fe enthalten für uns wenig Brauchbares, nur einige auf den Ackerbau bezügliche Opfergebräuche und wenige die Fruchtbarkeit und die Erzeugnisse des Landes betreffende Angaben. Abgedruckt ist der Bericht im 53. Bd. der Coleccion de Documentos inéditos para la Historia de España, ed. Navarrete, Madrid 1869.

15. Henrique Martinez lebte viele Jahre in Mejico und gab 1606 eine Historia de la Nueva España heraus. Was die Geschichte betrifft, so folgt er meist Acosta. Daneben giebt er aber zahlreiche und gute Beobachtungen über Astronomie, Geographie und Naturgeschichte des Landes.

II. Die zweite Klasse umfasst die Schriften solcher Autoren, die zwar ein oder zwei Generationen nach der Eroberung geschrieben haben, aber nie im Lande selbst gewesen sind.

1. Francisco Lopez de Gomara lebte in Sevilla und veröffentlichte 1553 eine Historia de las Indias und eine Crónica de la Nueva España. Obwohl er Zugang zu zahlreichen Originaldokumenteı hatte, sind ihm viele Irrtümer untergelaufen, die ihm namentlich BeRnaL Diaz nachweist und vorhält.

2. Gonsalez Fernandez de Oviedo y Valdez, geboren 1478 in Asturien, war Page am königlichen Hofe, als Columbus von seiner ersten Reise nach Hispaniola zurückkehrte, diente dann unter den spanischen Truppen in Neapel und war in den Jahren 1511-1514 Aufseher der Goldminen in Darien. Von 1535 an verwaltete er die Insel St. Domingo, machte sich aber durch seine Bedrückungen verhasst, so dass er 1545 zurückberufen wurde. Im Jahre 1547 ward er zum königlichen Historiographen ernannt. Schon 1525 war von ihm in Toledo ein Sumario de la historia general y natural de las Indias erschienen. Von 1535 an gab er in Madrid 20 Bücher der Historia general y natural de las Indias heraus, die anderen 30 wurden erst 1783 veröffentlicht. Sie enthalten recht viel über die Naturgeschichte des Landes, sind aber wohl nur für die Länder als zuverlässig zu nehmen, in denen er sich aufgehalten hat.

3. Antonio de Herrera, geboren 1559 zu Cuellar bei Segovia, wurde von Philipp II. zum Staatssekretär und Historio- 
graphen von Indien und Castilien ernannt. Er starb 1625. Ausser einer fast rein topographischen Descripcion de las Indias occidentales verfasste er eine Historia general de los hechos de los Castellanos en las islas y tierra firme del mar oceano 1492-1552, Madrid $1601-1615$ in 4 Bänden. Bei der Abfassung seiner Decades hatte er die zahlreichen Berichte vor sich, welche auf Befehl des Königs über den Zustand der einzelnen Provinzen von deren Verwaltern eingereicht worden waren. Auch sonst hatte er Zugang zu allen offiziellen Dokumenten; doch benutzte er das in ihnen enthaltene Material ziemlich unvollständig. In Betreff Mejicos hat er viel aus Acosta und GOMara genommen.

4. Antonio De Solrs, geb. 1610 in Alcala de Henares, war Sekretär Philipps IV. und seit 1661 auch Cronista mayor de Indias. Als solcher veröffentlichte er $1684 \mathrm{zu}$ Madrid eine Historia de la conquista de Mexico, die aber nur bis zur Eroberung der Hauptstadt durch Cortez geführt ist. Er benutzte seine Vorgänger und die ihm als Cronista zugänglichen Papiere. Wie er selbst in der Vorrede angiebt, kam es ihm nächst der Wahrheit hauptsächlich auf gute Stilisierung an. Sein Werk ist ein Panegiricus auf Cortez zu nennen und für uns ohne Bedeutung.

III. Die dritte Klasse besteht aus den Werken derjenigen, die zwar im Lande waren, aber erst über ein Jahrhundert nach der Eroberung. Ihre Mitteilungen über Sitten und Gebräuche haben immer noch Wert, denn wie religiöse Gebräuche und Aberglauben gehen auch die Gebräuche in Bezug auf den Landbau meist auf sehr frühe Zeit zurück.

1. Clavigero gab eine Storica antica del Messico zu Cesena 1780 heraus, die er ursprünglich spanisch geschrieben, dann aber ins Italienische übersetzt hatte ${ }^{1}$ ). Er rühmt sich alles gelesen und geprüft $\mathrm{zu}$ haben, was bis dahin veröffentlicht war. Seinen Aufenthalt in den versehiedenen Provinzen Mejicos giebt er auf 36 Jahre an, während welcher er die

1) Clavigero, Historia antigua de Megico, trad. del Italiano por José de Mora, Londres 1826. Bd. I. S. XII. 
Landessprache, die zablreichen historischen Malereien und Manuscripte studiert und viele erfahrene Leute um Rat und Auskunft angegangen hat. Seine Angaben sind daher ganz wertvoll ${ }^{1}$ ).

IV. In die vierte Klasse gehören die Werke der Reisenden dieses und des vorigen Jahrhunderts. Thre Angaben, sobald sie auf persönlicher Beobachtung beruhen, sind oft insofern von hohem Wert, als sie zweifelhafte Mitteilungen der alten Chronisten stützen können. Wenn sie uns z. B. von alten Gebräuchen berichten, so können wir wohl vermuten, dass sie zum Teil bis in die Conquistadorenzeit und noch weiter hinauf reichen. Das gilt besonders von den Volksbräuchen, die sich auf den Landbau beziehen; denn die ackerbautreibenden Völker sind im allgemeinen conservativ: wie die Väter thaten, so thun auch die Söhne. Solche Werke sind die von A. v. Humboldt, Trlor, Heller, MüHLenpfordt ete.

Da es bei Angaben über landwirtschaftliche Verhältnisse darauf ankommt, dass sie von Augenzeugen herrühren, so werden in erster Linie die Werke der ersten Klasse zu berücksichtigen sein, dann erst die der dritten und vierten Klasse. Die Zeugnisse aus der zweiten Klasse verdienen nur dann volle Glaubwürdigkeit, wenn sie durch andere gestützt werden.

Nach diesen Gesichtspunkten will ich versuchen, eine Darstellung der Bodenkultur im Reiche Montezumas zu geben, da wir über dessen Verhältnisse allein genügend unterrichtet sind.

\section{II.}

\section{Die Verteilung und Besitzart des Bodens.}

Das ganze urbare Land war zwischen der Krone, dem Adel, dem gemeinen Volk und der Geistlichkeit geteilt. Die der Krone gehörigen Ländereien, tecpantlalli genannt, wurden den tecpanpouhque oder tecpantlaca, d. h. den Leuten vom königlichen Palast oder der königlichen Kammer zur Bearbeitung überlassen. Für den Niessbrauch derselben hatten sie

1) Vgl. auch Prescott, a. a. O. Bd. 1. S. 47. 
keine Steuer $\mathrm{zu}$ entrichten ${ }^{1}$ ), höchstens gaben sie dem König einige Blütenzweige und gewisse kleine Vögel zum Zeichen der Abhängigkeit ${ }^{2}$ ). Dafür hatten sie die Verpflichtung, die königlichen Paläste und Gärten in Stand zu halten. Diese Ländereien erbten vom Vater auf den Sohn fort, konnten aber nicht veräussert werden, noch durfte sonst in irgend einer Weise über sie verfügt werden ${ }^{3}$ ).

Das Land der Adligen (oder die pillalli) war zweierlei Art. Die einen Ländereien gehörten dem Adel eigentümlich als Majorat oder zinsfreies Gut. Ihr Anrecht darauf leiteten die einen von einer ehemaligen Besitzergreifung her, als der betreffende Boden erobert und verteilt worden war. Die anderen hatten sie durch königliche Gunst einst empfangen und dann als Erbe-behalten. Viele hielten sich Pächter, welche die Felder bestellten und noch zu anderen Diensten verpflichtet waren. Diese Klasse des Adels konnte das Land verkaufen und sonst darüber verfügen, aber immer nur unter der Bedingung, dass es stets in Händen des Adels blieb. Gewöhnlich aber vererbten sie vom Vater auf den Sohn nach dem Recht der Erstgeburt, wobei die Töchter, wenigstens in der Provinz Tlaxcalla, nicht erbberechtigt waren. Die zweite Art der pillalli bestand aus solchen, welche der Herrscher zur Belohnung für geleistete Dienste verteilte. Das geschah stets nur auf Lebenszeit. Die Länder durften aber nicht weiter verpachtet oder gar veräussert werden ${ }^{4}$ ). Thre Inhaber bildeten die

1) Torquemada, Monarquia Indiana XIV c. 7. Carta de Martin Cortes in den Doc. inéd. de Indias Bd. 4 S. 444: Otras tierras habia que eran de Motezuma, las cuales se beneficiaban y sembraban y acudian con el rédito dellas á los calpisques y mayordomos que Motezuma tenia puestos en los lugares para cobrar sus tributos, y desto tomaban ellos para si y para su sustentacion una parte. Ixtlilxochitl, Hist. des Chichimèques, trad. p. Ternaux, Paris 1840 , cap. 35: Il y en avait d'autres (terres) connues sous le nom de Tecpantlali ou terres qui dépendent des palais des seigneurs. L'on nommait les Indiens qui les cultivaient tecpanpouhque ou gens qui dépendent du palais des chefs. $\left.{ }^{2}\right)$ Clavigero, Hist. antig. de Megico, Londres 1826. Bd. 1. S. 316. ${ }^{3}$ ) Torquemada, a. a. O. XIV c. 7. 4) Torquemada, a. a. O. XIV c. 7. Zurita, Rapport sur les diff. classes de chefs de la Nouv. Espagne, Paris 1840. S. 47 und 49 . 
zweite Klasse des Adels, die Teutley. ZuRITA ${ }^{1}$ ) vergleicht sie in ihrer Rangstellung mit den Komturen der Militärorden zu seiner Zeit. Sie alle waren steuerfrei, aber verpflichtet, in Kriegszeiten dem Herrscher mit ihrer Person, ihren Gütern und Vasallen Hilfe zu leisten.

Die Länder der einzelnen Gemeinden hiessen altepetlalli. Sie durften unter keinem Vorwand veräussert werden; nur im Falle eines öffentlichen Bedürfnisses der Gemeinde wurden sie an Mitglieder einer anderen Gemeinde vermietet. Unter keinen Umständen aber war es den Mitgliedern einer Gemeinde erlaubt (und noch zu Zuritas Zeit bestand dieses Verbot), auf den Äckern einer anderen zu arbeiten, um eine Mischung der Bewohner und einen Wechsel der Familien zu verhüten ${ }^{2}$ ). Jede Gemeinde (calpulli) erhielt ihr Land als gemeinschaftliches Eigentum, an dem jedes Mitglied Anteil hatte ${ }^{3}$ ). Jede Familie besass zu ihrem Unterhalt einen bestimmten Acker, der vom Vater auf den Sohn forterbte. Erlosch sie durch den Tod aller ihrer Glieder, so fiel ihr Land an den Calpulli zurück $^{4}$ ). Wer die Gemeinde verliess, ging seines Anteils ver-

1) a. a. O. S. 46. Teutley ist Plural, Tec Tecutzin Singular. Carta de Martin Cortes, a. a. O. S. 443: Habia otras tierras que llamaban pilales, y estas eran patrimonios de los principales, y venian de padres á hijos, y por estas no se pagaba tributo ninguno á Motezuma, escepto que los tales principales tenian cuidado de hacer algunas mantas de ricos plumajes para hacer presentes á Motezuma. Ixtlilxochitl, a. a. O.: Celles (terres) que l'on nommait Pillali appartenaient aux nobles et aux descendants des rois. D'autres appelées Tecpilali formaient le patrimoine des gentilshommes que l'on appelait les anciens seigneurs. On en donnait aussi à ceux qui avaient rendu des services. 2) Zurita, a. a. O. S. 53. Er war wahrscheinlich in den Jahren 1540-1560 in Amerika. 3) Carta de Martin Cortes a. a. O. S. 443: Las unas (tierras) llaman calpulales, y estas eran de Motezuma, y se repartian por suertes iguales de tantas brazas en largo y tantas brazas en ancho entre los mazeguales. ${ }^{4}$ ) $\mathrm{Zu}$ rita, a. a. O. S. 52. Ixtlilxochitl, Hist. des Chichimèques, cap. 35: D'autres champs se nommaient Colpollali ou Altepatlali, c'est-à-dire qui appartiennent à un quartier du village. C'était sur ces terres qu'étaient établis tous les gens du commun, qui les cultivaient pour vivre et les autres pour payer leurs tributs. Ces champs, qui formaient la plus grande partie du territoire des villes et villages, appartenaient aux rois ou aux seigneurs; 
lustig wie auch derjenige, welcher ihn drei Jahre lang ohne genügenden Grund unbebaut liegen liess ${ }^{1}$ ). Dieses Land erhielt der Calpulli ebenfalls zurück und man verteilte es an diejenigen Gemeindemitglieder, die es am meisten benötigten. Die Vorsteher der Gemeinden (callpullec oder chinancallec), deren Amt nicht erblich war ${ }^{2}$ ), nahmen die Verteilung des Landes vor und hatten die Pläne aufzubewahren, welche die einzelnen Felder, die Namen ihrer Eigentümer, ihre Lage und Grenzen, die Zahl der sie bestellenden Menschen verzeichnet enthielten, und darin die vorkommenden Veränderungen einzutragen ${ }^{3}$ ). Von dem Ackerland jeder Gemeinde war immer ein Teil abgetrennt, der gemeinsam bebaut wurde. Der Ertrag dieser Felder (milchimalli) war zum Unterhalt des Heeres in Kriegszeiten bestimmt ${ }^{4}$ ).

Schliesslich gab es noch Felder, welche den Priestern gehörten und zu ihrem Unterhalt bestimmt waren. Sie hiessen teutlales und wurden ebenfalls von den Gemeinden bestellt ${ }^{5}$ ).

Um nun die verschiedenen Ländereien leicht unterscheiden zu können, hatte man Pläne von den einzelnen Städten und Dörfern angefertigt, auf denen in verschiedenen Farben genau verzeichnet war, was jedem gehörte. Das Kronland war purpurrot gemalt, das Land der Calpulli hellgelb und das der Adligen scharlachrot ${ }^{6}$ ). Man konnte also mit einem Blick überschauen, wo die Grenzen jedes Dorfes waren und wem die Felder gehörten.

Die Bestellung des Bodens geschah durch die macehuales 7)

et les macehuales (c'est ainsi que l'on nommait ceux qui les cultivaient) ne pouvaient les donner à d'autres qu'à leurs enfants ou à leurs parents qui en héritaient sous les mêmes conditions qu'ils en avaient joui eux-mêmes.

1) Torquemada, a. a. O. XIV. c. 7. Zurita, a. a. O. S. 54 und 56. 2) Zurita, a. a. O. S. $\left.61 .{ }^{3}\right)$ Torquemada, a. a. O. XIV. c. 7 und Zurita, a. a. O. S. 61. 4) Torquemada, a. a. O. 5) Carta de M. Cortes a. a. O. S. 444: Habia otras tierras que llamaban teuteales (wohl teutlales), que eran del demonio y de los sacerdotes, y estas beneficiaban los mazeguales y acudian con el aprovechamiento dellas á los sacerdotes. ${ }^{6}$ ) Torquemada, a. a. O. ${ }^{7}$ ) Torquemada, a. a. O. II c. 89. Bei B. Diaz (Hist. verdad. de la N. España, Madrid 1795-1796) cap. 81 steht wohl ungenau macegales. 
und die mayegues oder tlamaïtes ${ }^{1}$ ), d. $\mathrm{h}$. Arbeiter auf fremdem Besitztum. Die letzteren wurden so genannt, um sie von den anderen steuerpflichtigen Klassen zu unterscheiden, die eigene Länder besassen oder dem Verbande eines Calpulli angehörten. Sie konnten das Land nicht wechseln und waren nur ihren Grundherren tributpflichtig ${ }^{2}$ ). Sie waren also so gut wie leibeigen. Die macehuales machten das niedere, gewöhnliche Volk aus ${ }^{3}$ ) und noch heute sollen sich die Eingeborenen Yucatans maceguales nennen ${ }^{4}$ ). An die Scholle gefesselt, wie wir oben gesehen haben, waren sie mit ihrer Person und ihrem Besitz steuerpflichtig. Der jährliche Tribut wird auf den dritten Teil vom Ertrage des Ackerbaus und der Viehzucht angegeben ${ }^{5}$ ). Das wäre ein hohe Besteuerung und wenn die Angabe auf Wahrheit beruht, was sich wohl schwer wird entscheiden lassen, können uns auch die Beschwerden gegen Montezuma und seine Steuerbeamten nicht Wunder nehmen. Als die Spanier ins Land kamen, klagten ihnen die Eingeborenen ihr Leid; sie müssten Holz, Steine, Mais zu Wasser und zu Lande transportieren, die Maisfelder der Adligen bebauen und ihre eigenen Ländereien zum Unterhalt des Heeres und der Geistlichkeit hergeben ${ }^{6}$ ). Diese Angaben sind vielleicht etwas übertrieben; denn ein anderer, wohl zuverlässigerer Gewährsmann stellt die Abgaben als leicht dar und doch sei bei der zahlreichen Bevölkerung ein bedeutender Betrag herausgekommen ${ }^{7}$ ). Sollten sie aber etwas Thatsächliches in sich bergen, so ist es wohl nur erklärbar durch den Umstand, dass

1) Zurita, a. a. O. S. 224 ff. und Herrera, Hist. gen. de las Indias Dec. III. lib. 4 c. 17 . Herrera hat die Schreibung mayeques. Für mayegues will Ternaux bei Zurita magueyes einsetzen und es mit den Magueyfeldern in Verbindung bringen. 2) a. a. O. Carta de Martin Cortes a. a. O. S. 450: Die principales setzten auf ihre Länder indios renteros, que acá llaman maeques, y estos les pagaban su tributo conforme á como se concertaban con ellos. ${ }^{3}$ ) Torquemada, a. a. O. II c. 89 und Zurita, a. a. O. S. 15. 4) Heller, Reisen in Mexico, Leipzig 1853. S. 263. 5) Gomara, Cronica de la N. Esp. cap. 77 bei Barcia, Histor. primit., Madrid 1749. Bd. II. Herrera, a. a. O. Dec. II lib. 7 c. 12. 6 B. Diaz, Hist. verdad. cap. 86. 7) Zurita, a. a. O. S. 68 und 242. 
zu jener Zeit die Kriege des Königs gegen die Spanier und die aufständischen Vasallenstaaten viele Hilfsmittel an Naturalien erforderten und so das Land natürlich schwer drückten.

Weit annehmbarer aber erscheint das, was MARTIN CoRTEZ darüber berichtet. Danach richtete sich nach der Grösse des Landbesitzes auch die Höhe der Abgabe, wobei die Fruchtbarkeit desselben nicht ausser Acht gelassen wurde. Derjenige, dessen Parzelle bewässert wurde, war doppelt so hoch besteuert wie der, welcher trockenen Boden besass. Im Übrigen waren alle diese Abgaben gleich ${ }^{1}$ ).

Die Abgaben, welche zu entrichten waren, bestanden immer aus den Erzeugnissen der einzelnen Gegenden ${ }^{2}$ ). Am gewöhnlichsten wurden sie also in Mais, Pfeffer (aji), Bohnen und Baumwolle bezahlt ${ }^{3}$ ), und zwar erhob man sie meist nach der . Ernte ${ }^{4}$ ). In Jahren der Dürre und Unfruchtbarkeit wurde keine Steuer eingefordert, vielmehr, wenn nötig, das Volk vom Herrscher mit Lebensmitteln und Saatkorn unterstützt ${ }^{5}$ ). War eine Gegend zu arm, so brachte der Bewohner seinen Tribut wenigstens in Läusen dar, ein eigentümlicher Brauch, der vornehmlich in der Provinz Mechoacan herrschte $\left.{ }^{6}\right)$. Während der Gefangenhaltung Montezumas fand ALONSO DE OJEDA, einer von Cortez' Offizieren, in einem Gemache des Palastes viele kleine volle Säcke. Einen derselben öffnete er in Gegenwart einiger Kameraden. Sein Inhalt bestand aus lauter Läusen.

1) Carta de Martin Cortes, a. a. O. S. 443: Conforme á la tierra que á cada uno se le daba, así pagaba su tributo. El que tenia una suerte de tierra, pagaba un tributo; y el que dos, dos; y el que tres, tres; y el que '́enia la suerte de tierra de regadio, pagaba un doblado que el que la tenia en secano. $\mathrm{Y}$ todos estos tributos eran iguales, de manera que conforme á esto, que es la verdad, ellos eran como los vasallos en España, porque Motezuma ú el que estaba en su nombre podia dar y quitar la tierra al que quisiesse con el mismo tributo, y dar á uno dos suertes, ú á otros tres, ú como el queria. 2) Suarez de Peralta, Tratado bei Zaragoza, Noticias Históricas, Madrid 1878. S. 21. 3) Z u rita, a. a. O. S. $\left.236 .{ }^{4}\right) \mathrm{Zurita}$, a. a. O. S. 246. 5) Herrera, Hist. gen. Dec. III lib. 4 c. 17 . Zurita, a. a. O. S. 250. Tezozomoc, Histoire du Mexique, éd. Ternaux, Paris 1853. cap. 39. 6) Herrera, a. a. O. Dec. II lib. 6 c. 17. 
Auf ihr Befragen, was das $\mathrm{zu}$ bedeuten habe, erfuhren sie dann, dass die Unterwürfigkeit gegen den König so gross wäre, dass der Ärmste und Schwächste, der nichts zu zahlen vermochte, wenigstens sich jeden Tag das Ungeziefer absuchen, sammeln und anstatt der Steuer als Zeichen der Unterthänigkeit abliefern musste. Schon zu Herreras Zeit, der uns den kleinen Zwischenfall berichtet ${ }^{1}$ ), bezweifelte man, dass es Läuse waren; aber ALonso DE OJEDA soll es, ebenso wie ALonso DE MATA, ausdrücklich in seinen Aufzeichnungen versichern. Man könnte hier an die Cochenillelaus denken, indessen wird die Richtigkeit jener Angabe durch den Umstand bestätigt, dass ein gleicher Brauch im Incareich bestand, wo man doch auf die Cochenille nicht zurückgehen kann. Sinchi Roca, der mit grosser Strenge darauf sah, dass ihm jeder Tribut zahlte, verlangte nach Unterwerfung der ausserordentlich armen Rivos von jedem wenigstens einen Gänsekiel voller Läuse als jährliche Abgabe ${ }^{2}$ ). Eine gleiche Verpflichtung hatten die Bewohner von Pasto ${ }^{3}$ ). Der Grund war der gleiche; PIEDRAHITA ${ }^{4}$ ) freilich giebt als solchen nur an, sie wären sehr unsauber gewesen und, damit sie sich reinigten, hätte ihnen der Inca Huayna Capac diesen Tribut auferlegt.

\section{III.}

\section{Pflanzenbau.}

Seit welcher Zeit man in Mejico begann Ackerbau zu treiben, wissen wir nicht. Nach Clavigero ${ }^{5}$ ), dessen Buch unter den späteren Werken in jeder Hinsicht die besten Angaben enthält und dem auch НuмвоцDт gefolgt ist, verwendeten schon die frühesten Bewohner des Plateaus von Anahuac grosse Sorgfalt darauf und unterrichteten die Chichimeken, ursprüngein Jägervolk, darin. Auch die später von Norden einwan-

1) Historia general Dec. II lib. 5 c. $8 .{ }^{2}$ ) Oliva, Histoire du Pérou, éd. Ternaux, Paris 1857. S. 42. 3) Herrerạ, a. a. O. Dec. V lib. 4 c. 2. 4) Historia de las conquistas del nuevo reyno de Granada, Amberes 1688. Lib. IV c. $\left.2 .{ }^{5}\right)$ Hist. antigua de Megico Bd. 1. S. 339. 
dernden Azteken waren ein Ackerbauervolk. Als sie freilich von den Colhuis und Tepaneken besiegt und auf die kleinen Inseln in den Seeen um Tenochtitlan beschränkt waren, stellten sie einige Jahre den Feldbau aus Mangel an dem nötigen Land fast ganz ein. Durch die Not getrieben sollen sie dann auf den Gedanken gekommen sein, auf den Seeen schwimmende Felder herzustellen, woher man die Entstehung der sog. Chinampas (s. unten) leitet. Sobald sie aber das Joch der Tepaneken abgeschüttelt hatten, begannen sie wieder sich mit grossem Fleiss auf den Ackerbau zu werfen. Für das hohe Alter des Feldbaus und die Achtung, die man ihm zollte, scheint auch zu sprechen, dass sie eine der Ceres entsprechende Göttin (Chicomecoatl) verehrten. Sie soll die erste. Frau gewesen sein, welche Brot und andere Speisen zu bereiten verstand. Dargestellt wurde sie nach SAHAGuns Schilderung mit einer Krone auf dem Haupt und in der Rechten ein Gefäss haltend; ihre Fussbekleidung war ganz rot gemalt ${ }^{1}$ ). Im ethnographischen Museum zu Berlin befindet sich ein Steinbild der Göttin und hier hält sie in der linken Hand zwei Maiskolben. Auch Torquemada ${ }^{2}$ ) erwähnt die mejicanische Ceres, aber unter dem Namen Xilonen. Ihr zu Ehren wurde im Monat Hueytecuhilhuitl ein Fest gefeiert, an dem vom Könige die Armen und Notleidenden mit Nahrungsmitteln reichlich versorgt wurden.

Am Anfang des 16. Jahrhunderts lässt A. v. НuмвоLdт ${ }^{3}$ ) den Rio Grande de Santiago die Grenze zwischen den ackerbautreibenden Völkern von Anahuac und den nördlichen Jägervölkern bilden. Die Chichimeken und Guachiles (nördlich vom Santiago) lebten den grössten Teil des Jahres von den Früchten der Tuna (Cactus tuna), des Mesquite oder Johannesbrotbaumes (Algarrobia oder Prosopis glandulosa) und der Maguey, machten auch keinen Gebrauch von den vielen vorhandenen

1) Sahagun, Historia general de las cosas de Nueva España, ed. por C. M. de Bustamente, Mexico 1829. Lib. I cap. 7. 2) Monarquia Ind. X c. $19 .{ }^{3}$ ) Essai politique sur le royaume de la Nouvelle Espagne, Paris 1811. Bd. 1. S. 218. 
Cochenilleläusen ${ }^{1}$ ). Schon etwas südlich der Mündung jenes Flusses gab es keinen Ackerbau mehr. Die Bewohner der dort gelegenen Insel Santa Cruz fanden die Spanier noch im Zustand der Wildheit vor; sie nährten sich blos von wildwachsenden Früchten, von der Jagd und vom Fischfang ${ }^{2}$ ).

Bei dem Fehlen jeder Art von Zugvieh musste die Feldbestellung ganz durch Handarbeit besorgt werden. Es fand denn auch der grösste Teil der Bevölkerung beim Ackerbau Verwendung. Ausser dem König, dem hohen Adel und dem stehenden Heere waren alle Arbeiter und verbrachten, mit wenigen Ausnahmen, ihr Leben in der Feldbestellung ${ }^{3}$ ). Ihr Fleiss wird allgemein von den spanischen Geschichtsschreibern gerühmt. Schon CorTEz erwähnt denselben in seinen Berichten an den Kaiser. Ihm und seinen Begleitern fielen auf dem Zuge von der Küste nach der Hauptstadt sofort der gute Anbau des Bodens, der Reichtum des Landes und die Menge seiner Bewohner auf. Sie waren höchlichst überrascht von der Grösse der Ortschaften, durch welche sie zogen, und der Menschenmenge, die von überall herbeiströmte, so dass das kleine Heer kaum auf der Strasse vorwärts kommen konnte ${ }^{4}$ ).

Von der alten Betriebsamkeit scheint unter den heutigen Indianern noch etwas erhalten $\mathrm{zu}$ sein. Meistenteils macht man ihnen den Vorwurf eines Hanges zur Unthätigkeit und Trägheit. MÜHLENPFORDT ${ }^{5}$ ) kann dieser Meinung nicht beipflichten. Er hält die heutigen ansässigen Indianer, welchen die Eroberer statt der alten, von ihnen zerstörten einen niedrigen Grad europäisch-spanischer Kultur eingeimpft kaben, immer noch für die eigentliche, wahre Arbeitsklasse Mejicos. Sie bebauen das Feld, sie arbeiten als Tagelöhner auf den Landgütern, in den Städten und sie versorgen die Märkte der Städte mit den Erzeugnissen ihrer Felder, ihrer Gemüse- und Fruchtgärten.

1) Herrera, Hist. gen. Dec. IV lib. 9 c. $\left.12 .{ }^{2}\right)$ B. Diaz, Hist. verd. cap. 200 und Gomara, Cronica de la Nueva España cap. 118, bei Barcia, Histor. primit. Bd. II. ${ }^{3}$ ) Torquemada, a. a. O. XIII c. 31. 4) B. Diaz, Hist. verd. cap. 45 , c. 68 , c. 87 , c. 130 . 5) Schilderung der Republik Mexico, Hannover 1844. Bd. I S. 238. 
a) Herstellung und Bearbeitung der Felder.

Hätte sich Mejico eines grösseren und vor allem besser verteilten Niederschlags zu erfreuen, so würde es zu den fruchtbarsten Ländern der Erde gehören. Schon CoRTEz' Gefährten fiel die Fruchtbarkeit des Landes auf. „Die Felder", schreibt einer derselben ${ }^{1}$ ), „gewähren den herrlichsten Anblick. Die Triften sind mit den schönsten Kräutern bedeckt und das Gras reicht dem Fussgänger bis zur halben Höhe des Beines. Der Boden bringt Alles, was man darin sät, im grössten Ueberflusse hervor und an manchen Orten gestattet er jährlich eine zwei- bis dreifache Nutzung." Allein die ungleiche Verteilung des Niederschlags vermindert oft den reichen Ernteertrag. Nur da ist die Ernte sicher, wo der Boden künstlich bewässert werden kann. Wo dies nicht angeht, hängt der Erfolg fast ausschliesslich von dem zeitgemässen Eintritt der Regenzeit ab. Man kennt nur zwei Jahreszeiten in Mejico, selbst bis zum 28. Parallelkreis nach Norden. Die Regenzeit beginnt gewöhnlich Anfang Juni. Dauert die Trockenheit bis Ende Juni, so leidet das Getreide überall, wo nicht künstliche Bewässerung angewandt wird. Die Regen fallen bis September oder Oktober und dann folgt während 8 Monate die Trockenzeit ${ }^{2}$ ).

Diese wenig holden Verhältnisse haben die Bewohner jedenfalls schon in früher Zeit zur künstlichen Bewässerung geführt. Man leitete die Flüsse, die sonst meist in tiefen Becken dahinströmen und so dem Lande wenig Nutzen bringen, von den Bergen herab und in Kanälen über die Felder. In dieser Weise wurde in der Ebene von Izcuzan und um Chololla von dem fruchtbaren Boden ein reicher Ertrag gewonnen. Hier war daher die Bevölkerung verdichtet und das Land besser ausgenutzt, so dass nach der übertreibenden Redeweise der Chronisten keine Handbreit leer war $^{3}$ ). Die Länder mit künst-

1) Ramusio, Navig. e viaggi, Venet. 1556. Bd. III fol. $304 .{ }^{2}$ ) A. v. Humboldt, Essai politique Bd. 3. S. 73. ${ }^{3}$ ) Gomara, Cronica de la N. España cap. 61 und 116. Ebenso war es in Meztitlan: El rio, que pasa por este valle de Meztitlan, es rio caudal . . .; los naturales se 
licher Bewässerung führten den Namen atlalli, d. h. Wasser oder das Land, das bewässert werden kann, während die trockenen, auf denen deswegen nichts wuchs, teuhtlalli (von teuhtli Staub) und die ebenso unfruchtbaren Sandfelder xalalli hiessen ${ }^{1}$ ). Das fruchtbare und ertragreiche Saatland nannte man atoctli, d. h. das vom Wasser gebrachte Land, oder tlalcoztli, d. i. gelbes Land ${ }^{2}$ ). Trat Wassermangel ein, so wurde dem Wassergott Tlaloc ein Opfer in Gestalt einiger Kinder gebracht. Die grausame Sitte soll zu einer Zeit aufgekommen sein, als es 4 Jahre lang nicht regnete und nichts Grünes mehr auf den Feldern zu sehen war ${ }^{3}$ ).

Heute hat man natürlich die künstliche Bewässerung zum grössten Teil ruhen lassen. In dieser Hinsicht vergleicht TyLoR ${ }^{4}$ ) ganz passend Spanien und das mejicanische Hochland. In beiden Ländern haben wir nicht gerade Regenmangel, sondern nur eine dem Ackerbau nicht dienliche Verteilung des Niederschlags. Die ausgewühlten Betten der Flüsse und Bäche zeigen deutlich, mit welcher Gewalt die Wassermassen herabstürzen und wie sie dem Lande mehr Schaden als Segen bringen. Seltsam genug sind beide Länder einst im Besitz von Völkern gewesen, die da wussten, dass das Wasser das Lebensblut des Bodens ist, und deshalb mit aller Kraft daran arbeiteten, dieses Blut gleichsam in Adern über seine Oberfläche $\mathrm{zu}$ verteilen. In beiden Ländern wurden die Völker von den Spaniern besiegt und die so mühsam erbauten Bewässerungsanlagen dem Verfall preisgegeben. Als die Mauren aus Andalusien und Granada vertrieben waren, kamen Kolonisten aus den nördlichen Provinzen an ihre Stelle, welche

aprovechan en algunas partes del riego deste rio, y cogen cantidad de semillas de axi, frisoles y chian. Puedese regar todo el valle, porque el rio es muy aparejado para sangrarle y sacar muchas acequias de agua (Relac. de la prov. de Meztitlan in den Doc. inéd. de Indias Bd. 4. S. 546).

1) Sahagun, Hist. gen. de las cosas de N. Esp. Lib. XI c. 12 § 3 und 4. 2) Sahagun, a. a. O. Lib. XI c. $12 \S 3 .{ }^{3}$ ) Ritos antiguos, sacrif. é idol. de los Indios de N. Esp. in den Doc. inéd. para la Hist. de España Bd. 53. S. 350. $\left.{ }^{4}\right)$ Anahuac or Mexico and the Mexicans, ancient and modern, London 1861. S. 158. 
die Bewässerungskanäle in Stand zu halten nicht für nötig fanden, wiewohl sie doch ihre Vorteile klar vor Augen hatten. Nicht anders geschah es in Mejico. Freilich darf man auch in Bezug auf den Ackerbau die alten Mejicaner nicht mit den spanischen Arabern vergleichen; aber in den dichter - bewohnten Teilen der Ebenen werden auch sie bedeutende Fortschritte darin gemacht haben. Dagegen in den Gegenden mit dünner Bevölkerung rissen sie wahrscheinlich den Boden nur leicht auf und bewässerten ihn aus irdenen Krügen, wie es dort noch heute der Fall ist ${ }^{1}$ ). Bastian beschreibt eine solche Eimrichtung, eine Art persischen Wasserrades, um einen kleinen Streifen des anliegenden Landes zu tränken. „Das Rad war mit einem Kreise seitwärts geneigter Krüge so gestellt, dass es durch den Strom des Flusses selbst gedreht wurde und ebenso seine Krüge von selbst, sobald sie oben anlangten, auf das Ufer entleerte. Dadurch ward ein Bassin mit Wasser gefüllt, aus dem Kanäle in die umliegenden Ländereien ausliefen, und jeder Gutsbesitzer hatte seinen Tag der Woche und seine Stunden des Tages, wo ihm die Benutzung der Schleusen für seinen Anteil zustand“2). Zu НимвоLDTs Zeiten ward die künstliche Bewässerung in grossem Massstabe besonders in den reichen Ebenen am Rio Grande de Santiago und denjenigen zwischen Salamanca, Irapuato und La Villa de Leon angewendet ${ }^{3}$ ).

In anderer Weise wurde dem Wassermangel, wenigstens um Mejico herum, durch die sog. Chinampas oder schwimmenden Gärten abgeholfen, eine Einrichtung, die zugleich Zeugnis ablegt von der sorgfältigen Ausnutzung jeglicher Fläche für den Unterhalt der Bewohner. Man benutzte nämlich auch die grossen Seeen um Tenochtitlan zur Gewinnung von Nahrungsmitteln ${ }^{4}$ ). Die Entstehung der Chinampas ist schon oben angedeutet worden ${ }^{5}$ ). HumboLdT ${ }^{6}$ ) lässt ihre Erfindung bis ins 14. Jahr-

1) E. B. Tylor, a. a. O. S. 159. 2) A. Bastian, Geographische und ethnologische Bilder, Jena 1873. S. 414. 3) Humboldt, Essai politique. Bd. 3. S. 75. ${ }^{4}$ ) Torque mada, Mon. Ind. XIII c. $32 .{ }^{5}$ ) S. 14. Einen anderen Bericht über die Entstehung der chinampas giebt Martinez, Historia de la Nueva España, Megico 1606. Doch ist er weniger an- 
hundert aufsteigen: „Sie hat ihren Grund in der aussergewöhnlichen Lage eines Volkes, welches rings von Feinden umgeben und gezwungen, inmitten eines wenig fischreichen Sees zu leben, über die Mittel zu seinem Unterhalte nachgrübelte. Wahrscheinlich hat die Natur selbst den Azteken die erste Idee zu diesen schwimmenden Gärten eingegeben. An den sumpfigen Ufern der Seeen von Xochimilco und Chalco reisst die starkbewegte Wassermasse zur Zeit des Hochwassers mit Kräutern bedeckte und von Wurzelwerk durchzogene Erdschollen los. Nach langem Hin- und Hertreiben durch den Wiıd vereinigen sich diese Schollen bisweilen zu kleinen Inselchen. Ein Stamm, der zu schwach war, sich auf dem Festlande zu halten, glaubte diese Stücke Bodens benutzen zu müssen, die ihm der Zufall anbot und deren Besitz ihm kein Feind streitig machte." Dieses System des Ackerbaus wurde dann allmählich von den erfinderischen Azteken vervollkommnet. „Die schwimmenden Gärten, welche die Spanier in grosser Menge vorfanden, waren

sprechend als der Clavigeros. „El sitio de la laguna á donde los Mexicanos avian fundado su ciudad, pertenecia y era termino de Atzcapozalco, á cuyo rey pagauan por esto tributo, el qual temiendose de la felicidad de los Mexicanos, procuró de oprimirlos y tener los sugetos, y con este intento los demandó entre otras cosas del tributo una cosa extraordinaria entendiendo que no lo podrian dar, para con esta ocasion destruyrlos, y era, que avian de hazer una sementera en el agua de varias frutas $y$ legumbres, y que nacida y criada toda la sementera se le auian de traer cada año. Los Mexicanos y su Rey recibieron pena desto, pareciendoles cosa ympossible, mas en fin la hizieron como se pidio, porque sobre juncia y carizos se echa tierra de tal forma que no la deshaze el agua $y$ sobre ella se siembra y cultiva, crece y madura y se lleva entre canoas de una parte á otra, como se ve de ordinario en esta laguna de Mexico y assi lo hizieron entonces y llevaron al Rey de Atzcapozalco el tributo demandado, el qual se admiró dello y les demandó para adelante otro tributo mas dificultoso, con tanta soberuia que puso de nuevo á los Mexicanos en afliccion, mas su ydolo los conforto diziendo, que no tuuissen pena y estuuiessen eiertos que vendria tiempo en que los de Atzcapozalco pagarian aquellos antojos con las vidas, y que por entonces era bien obedecerles" (a. a. $O$. Tratado 2 cap. 12). Das geschah zur Zeit des ersten Königs der Mejicaner, welcher nach Martinez (Trat. 2 cap. 32) von 1384 bis 1424 regierte. 6) Essai politique Bd. 2. S. 185 . 
Flösse von Schilf (totora), Aesten, Wurzeln und Buschgezweig. Die Indianer bedecken diese leichten und eng verflochtenen Gestelle mit schwarzer Erde, welche von Natur reich an Kochsalz ist. Nach und nach entfernt man das Salz durch Begiessen der Erde mit dem Wasser des Sees, und der Boden wird um so fruchtbarer, je öfter man diese Auslaugung wiederholt. Das Verfahren gelingt selbst mit dem salzigen Wasser des Sees von Tezcuco, weil dasselbe, vom Sättigungspunkt sehr entfernt, noch Salz zu lösen fähig ist." Wenn bei den Chinampas auf dem Chalco, der ein Süsswassersee war und ist, das Entsalzen nicht nötig war, so ist das nicht eine Folge des süssen Wassers, wie TrLOR anzunehmen scheint ${ }^{1}$ ), sondern jedenfalls ist ihr Boden nicht so salzhaltig und damit das Wachstum der Pflanzen nicht ausgeschlossen. Bisweilen tragen die Chinampas sogar die Hütte des sie bewachenden Indianers. "Nach Belieben zieht man sie mit Seilen oder stösst sie mit langen Stangen von einem Ufer zum anderen. Jeder Chinampas bildet ein Parallelogramm von $110 \mathrm{~m}$ Länge und $5-6 \mathrm{~m}$ Breite $^{2}$ ). Enge und symmetrisch unter einander verbundene Gräben trennen diese Vierecke. Die Gartenerde, welche durch das häufige Begiessen entsalzt ist, erhebt sich gegen $1 \mathrm{~m}$ über die umgebende Wasserfläche. Der Rand der Vierecke ist gewöhnlich mit Blumen und manchmal sogar mit einer Rosenhecke eingefasst. Auf ihnen werden alle möglichen Gartengewächse gebaut, die auf dem beständig benetzten Boden natürlich vortrefflich gedeihen" ${ }^{3}$ ). Die Zahl der schwimmenden Gärten wird in früheren Jahrhunderten eine weit grössere gewesen sein. Mit den Bauten behufs Tieferlegung des Wasserspiegels der Seeen, die schon im Aztekenreich begonnen und nach der spanischen Eroberung weiter geführt wurden ${ }^{4}$ ), schrumpften

1) Tylor, a. a. O. S. $\left.62 .{ }^{2}\right)$ Nach Clavigero (Hist. antig. de Megico, Bd. 1. S. 339) waren sie gewöhnlich 8 Toisen lang, 3 breit und ragten nicht ganz 1 Fuss (Pariser Mass) über die Oberfläche des Wassers empor, waren also viel kleiner. $\left.{ }^{3}\right) \mathrm{Humboldt}$, a. a. O. ${ }^{4}$ ) Fray Pedro Simon, Primera Parte de las Noticias historiales de las conquistas de tierra firme en las Indias Occidentales, Cuenca 1627, Not. I cap. 10 no 3 : el año de 1604 cerca de la ciudad de Mexico, trasminando un cerro tan 
sie zugleich mit den Seeen mehr und mehr zusammen ${ }^{1}$ ). Um die Wende des 16. zum 17. Jahrhundert scheint eine Katastrophe über sie hereingebrochen zu sein. Die Gräben, durch welche das Wasser der Seeen abfloss und welche zugleich zur Verteidigung der Stadt dienten, wurden geschlossen und damit waren die Ländereien vernichtet, so dass kaum noch etwas Saatland vorhanden war. Eine Hungersnot soll bei den Bewohnern entstanden sein, viele verliessen ihre Felder und gingen anderswohin, um sich Brot zu suchen ${ }^{2}$ ). Jetzt sind die wirklich schwimmenden Gärten, welche sich noch zu

alto que tiene de subida mas de una buena legua, y otro tanto de baxada, para por alli desaguar la Laguna, en que esta fundada la ciudad, por no verse en los peligros que poco antes avia tenido con crecidas y inundaciones.

1) Schon am Ende des Jahrhunderts, in welchem die Spanier ins Land kamen, waren die Ufer des Sees von Mejico bedeutend zurückgewichen, so dass man teilweise den Boden, welchen früher das Wasser bedeckt hatte, beackerte. Den Grund für das Zusammenschrumpfen sieht Martinez in der Zuschüttung des Sees durch das Erdreich, welchen die in ihn sich ergiessenden Flüsse hier niederfallen lassen. „Refieren las historias que quando los Christianos vinieron á Mexico llegava la laguna della por la parte del norte hasta el cerro de Tenayuca, y por la banda del sur hasta el pueblo de S. Matheo, y al Occidente se estendia por todos los llanos entre Chapultepec y Tlalnepantla. Al presente vemos en algunas de las referidas partes (que conocidamente fue laguna) buenas eredades y labores; de donde se puede conjecturar, que si en los pocos años que an passado desde que los altos y contornos de la laguna se aran y labran, an los aguaceros traydo tanta tierra á los llanos como queda referido y vemos y an descarnado algunas tierras de los altos, de modo que está agora en ellas descubierto el Tepetate, se puede presumir, que por discurso de tiempo se alçara el suelo de la laguna y la tierra en el contorno de la ciudad de Mexico de tal manera que venga á emparejar con la ciudad, y aun sobre pujarla, respecto de que tambien el sitio de la ciudad (como lo mas dello es tierra mouediza y salitrosa) se consume y abaxa con la humidad y peso de los edificios. Digo pues, fundando mi parecer sobre las referidas razones, que la laguna de Mexico y Tetzcuco no mengua, pues siempre entran en ella las aguas que solian entrar, sino que el suelo y la tierra ala redonda della crece, haziendo que se estreche y leuante el vaso della, y podria ser por discurso de tiempo llegar á tanto, que la ciudad recibiesse detrimento dello" (M artinez, a. a. O. Tratado 2 cap. 15). ${ }^{2}$ ) Torquemada, a. a. O. XIII c. 32. 
Anfang des Jahrhunderts auf dem See von Chalco befanden und von HUмBоLD'T beschrieben sind, gänzlich verschwunden. Seitdem führen die längs den Kanälen sich hinziehenden Streifen Land den Namen der jardines flotantes ${ }^{1}$ ).

An hohen Orten und auf den Abhängen der Berge säete man nicht Jahr für Jahr, sondern liess das Land brach liegen, bis es sich mit einer Pflanzendecke und mit Gestrüpp bedeckt hatte. Dann wuirde das ganze Stück Boden abgebrannt, um mit der Asche die durch die Regengüsse ausgelaugte Erde zu düngen ${ }^{2}$ ). Die Äcker am Abhang der Berge und Hügel wurden tepetlalli genannt und, wenn sie voller Steine lagen, tetlalli. Das von den Bergen herabgeschwemmte Erdreich bildete die xalatoctli, die natürlich leichter zu bearbeiten waren. Sallalli war der Boden, auf dem früher Gebäude gestanden hatten und der dann umgegraben war; er gab einen reichen Ertrag, wie man sehr wohl wusste ${ }^{3}$ ).

Das Werkzeug, dessen man sich bei der Umwendung des Bodens bediente, soll nach Clavigero ${ }^{4}$ ) von Kupfer gewesen sein, mit einem hölzernen Stiel versehen, aber von unserem Spaten ganz verschieden. Es hiess coa oder coatl und man hat ihm den Namen wohl nach seiner Gestalt gegeben ${ }^{5}$ ). Allein die von mir benutzten Quellen sprechen nur von Holzschaufeln ${ }^{6}$ ). Es waren Pfähle aus starkem Eichenholz, die am Ende die Breite einer Hand hatten und späterhin mit Eisen besetzt waren ${ }^{7}$ ). Man nannte sie huictli und ihre Form wechselte nach den Provinzen ${ }^{8}$ ). Die eine Art handhabte man nur mit

1) Mühlenpfordt, Schilderung der Republik Mejico. Bd. 2. S. 342 und Tylor, a. a. O. S. $63 .{ }^{2}$ ) Torquemada, a. a. O. XIII c. 32. $\left.{ }^{3}\right)$ Sahagun, a. a. O. Lib. XI c. $12 \S 3 .{ }^{4}$ ) a. a. O. Bd. 1. S. 340. 5) Cohua oder cohuatl heisst die Schlonge. ${ }^{6}$ ) Gomara, Hist. de las Indias cap. 215 bei $\mathrm{Barcia}$, Histor. primit. Bd. 2. ${ }^{7}$ ) Herrera, Hist. gen. Dec. IV lib. 9 c. $13 .{ }^{8}$ ) Torquemada, a. a. O. XIII c. 31: Tambien quedo en ellos el modo rustico de cultivar las tierras con palas de palo, que llaman huictli, hechas de madera de encina, que son mui fuertes y segun las Provincias, asi varia la forma de estos instrumentos, aprovechandose de ellos, unos con solas las manos, sentados en cuchillas o sobre los pies; y otros, con manos, y pies, hincandolos en la tierra, a fuerza de pies y manos. 
den Händen, indem man auf den Füssen hockte; die andere wurde mit vereinter Kraft von Hand und Fuss in die Erde getrieben. Vielleicht gebrauchten sie auch Stäbe mit einer Feuersteinschneide an der Spitze, wie ein solcher im Museum zu Berlin zu sehen ist. Cuavigero glaubt, dass sie gewiss noch andere ländliche Instrumente besessen haben, nur hätten uns die alten Chronisten nichts davon ïberliefert. Dagegen lässt sich anführen, dass man bis jetzt noch keine Funde gemacht hat.

Bei allen Feldarbeiten halfen die Frauen und die Kinder ${ }^{1}$ ). Die Männer richteten das Land zu und die Frauen säeten hinter ihnen hergehend das Korn. Bei der Ernte mähete der Mann, während die Frau das Abstreifen der Ähren und Reinigen des Kornes besorgte. Ausführlich beschreibt Clavigero ${ }^{2}$ ) die ehemalige Art des Säens, die auch noch zu seiner Zeit an einigen Orten in Gebrauch war. Mit der Spitze eines im Feuer gehärteten Stockes machte man in den Boden ein Loch, warf aus einem über der Schulter hängenden Korbe ein oder zwei Maiskörner hinein und deckte mit dem Fusse etwas Erde darauf. In einiger Entfernung davon wurde ein neues Loch gestossen, und so ging man in grader Linie bis an das Ende des Feldes. Sie besassen darin eine grosse Geschicklichkeit, so dass die Saatreihen alle parallel waren und die Löcher in gleicher Entfernung von einander. Wenugleich etwas langsam, war diese Art des Säens doch von nicht zu unterschätzendem Vorteil; denn der Boden erhielt dadurch die für ihn passende Kornmenge und der Mais wurde nicht unnuitz ausgesät. In der That sollen so bestellte Äcker überreiche Ernten geliefert haben. Sobald die junge Pflanze eine gewisse Höhe über dem Erdboden erreicht hatte, häufte man am Fusse etwas Erde auf, damit sie saftiger würde und besser dem Winde widerstehen könnte. Hieran knüpften sich verschiedene Gebräuche. Wenn der Mais über $1 / 5 \mathrm{~m}$ aus der Erde hervorgekommen war, fand in den Dörfern, die den Vornehmen gehörten, ein

1) Torquemada, a. a. O. und Zurita, a. a. O. S. 133. 2) a. a. O. Bd. 1. S. 340 r. 341 ; vgl. auch Oviedo, Hist. gen. lib. 7 c. 1. 
Opfer eines Knaben und eines Mädchens im Alter von 3 bis 4 Jahren statt ${ }^{1}$ ). Am Tage Behitozoz-thi, d. h. wenn der Mais einem bis ans Knie reichte, sammelte jeder auf seinen Maisfeldern einige Stengel und opferte, in Decken gehüllt, vor diesen Maispflanzen etwas Speise, Trank und Weihrauch $(\text { Copali) })^{2}$.

Zur Entkörnung der Ähren sollen sie Tennen gehabt haben ${ }^{3}$ ), was aber wenig wahrscheinlich ist, und zur Aufbewahrung des Kornes Speicher, die von quadratischer Gestalt und für gewöhnlich aus $\mathrm{Holz}$ waren. Einzelne derselben waren angeblich so geräumig, dass sie 5-6000 und mehr Fanegas Mais fassen konnten ${ }^{4}$ ), auf welche Zahlen natürlich kein Gewicht zu legen ist.

Um die Saatfelder pflegte man kleine Gerüste aus Holz, Zweigen und Schilf herzustellen, von denen aus ein Mann, gegen Sonne und Regen geschützt, die Felder bewachen und mit der von ihnen mit grosser Geschicklichkeit gehandhabten Schleuder die Vögel treffen konnte, welche das Saatkorn vertilgten oder sonstigen Schaden anrichteten ${ }^{5}$ ). Meist mussten sich die Knaben auf die Gerüste oder auch auf Bäume stellen, wenn solche vorhanden waren ${ }^{6}$ ).

Auch für Düngung sorgte man. Das so verbesserte Land hiess tlalaviac. Geschah die Düngung durch verfaulendes Holz, so nannte man die so kultivierten Felder quauhtlalli. Auf den tlacotlali wurden Pflanzen als Dung in die Erde eingegraben ${ }^{7}$ ). Auch Menschenkot wird wahrscheinlich verwendet worden sein. Wenigstens war solcher in ganzen Kahnladungen in den Buchten des Sees von Mejico unfern des Marktplatzes zum Verkauf aufgestellt. Als seine Verwendung wird freilich das Gerben von Leder angegeben, woran aber wohl kaum zu

1) Ritơs ant., sacrif. é idol. de los Indios de la N. Esp. in der Col. de Doc. inéd. para la hist. de España. Bd. 53. S. $349 .{ }^{2}$ ) a. a. O. S. 351. $\left.\left.{ }^{3}\right) \mathrm{Clavigero,a.a.} \mathrm{O.}{ }^{4}\right)$ Ausser Clavigero vgl. auch Torquemada, a. a. O. XIV c. 16. 5) Clavigero, a. a. O. Bd. 1. S. $342 .{ }^{6}$ ) Oviedo, Hist. gen. Lib. 7 c. $\left.1 .{ }^{7}\right) \mathrm{S}$ ahagun, Hist. gen. de las cos. de N. Esp. Lib. XI c. 12 § 3 . 
denken ist. Überhaupt waren aller Orten Anstalten zum Sammeln desselben angelegt ${ }^{1}$ ).

Umgrenzt waren die einzelnen Felder mit Steinmauern oder Reihen von Maguey, die sich dazu vorzüglich eignet. Letzteres wird darum auch das häufigere gewesen sein. Im Monat Panquetzalitzli, unserem Dezember entsprechend, wurden jedes Jahr die erforderlichen Reparaturen vorgenommen ${ }^{2}$ ).

\section{b) Kulturpflanzen.}

Das Hauptnahrungsmittel und die am meisten angebaute Frucht war der Mais, tlaolli oder centli genannt. Es unterliegt wohl keinem Zweifel mehr, dass Amerika das Vaterland des Maises ist, nachdem die Euchlaena luxurianus Durieu et Ascherson in Guatemala durch Rossignon entdeckt ist und Ascherson auf die Ähnlichkeit zwischen Euchlaena und Zea Mays hingewiesen hat ${ }^{3}$ ). Welcher Teil von Amerika aber es ist, lässt sich nicht mit gleicher Gewissheit bestimmen. DECANDOLLE vermutete Südamerika, noch eher Mejico, und bei der Nähe von Mejico und Guatemala kann man jetzt, nach der Entleckung der verwandten Euchlaena luxurianus in Guatemala, wohl um so mehr sich der Ansicht hinneigen, dass Mittelamerika als sein Vaterland anzusehen ist. Merkwürdigerweise verlegt auch eine Erzählung von der Auffindung der Maispflanze durch QueTzalconuátL, die sich in den alten Überlieferungen findet, den Schauplatz dieses denkwürdigen Ereignisses in die Gegend des heutigen Guatemala. Als QuETZaLcoHUatl von Xicalanco an der Küste von Tabasco aus nach einer für den Ackerbau geeigneten Pflanze auf die Suche geht, findet er in dem Mais eine solche und zwar in einer Gegend, die in allen zum Majastamm gehörigen Sprachen Paxil-Cayalà

1) B. Diaz, Hist. verdad. cap. 92. 2) Clavigero, a. a. O. Bd. 1. S. 340 ; Torquemada, a. a. O. XIII c. 32 . 3) L. Wittmack, Über antiken Mais aus Nord- und Südamerika. Zeitschr. für Anthropologie, herausg. von R. Hartmann, R. Virchow, A. Voss. XII. Jahrg. Berlin 1880. S. 86 . . 
heisst. Alles lässt vermuten, dass sie dem Reiche Xibalba oder Palenque tributpflichtig war ${ }^{1}$ ).

Wie schon erwähnt worden, ward der Mais so gesät, wie bei uns die Bohnen. In den heissen und feuchten Gegenden kann der Mais zwei bis drei Ernten im Jahre geben, aber gewöhnlich lässt man es bei einer bewenden ${ }^{2}$ ). Wenn GovarA ${ }^{3}$ ) berichtet, an vielen Orten werde er drei Mal im Jahre gesät und gäbe einen 300- und sogar 500fältigen Ertrag, so hat das wohl nur für jene begünstigten Stellen des Landes Anspruch auf Wahrheit oder für solche, wo man sich die Mühe der künstlichen Bewässerung machte. Dieselbe Fruchtbarkeit wird von Guatemala (Quauhtemallan) erwähnt. Man erntete dort in der bewässerten Ebene von 1 Fanega Mais 100, 200 und selbst 500; dabei soll sich der dortige Mais durch die Grösse seines Stengels, seiner Ähre und seines Kornes ausgezeichnet haben ${ }^{4}$ ). Weit weniger hoch giebt Oviedo ${ }^{5}$ ) den Ertrag an, seine höchste Zahl ist 150. Aus diesen so abweichenden Angaben lässt sich auf die Production des Landes zur Zeit der Froberung kein sicherer Schluss ziehen, zumal die Mitteilungen selbst schon keinen Anspruch auf ein bescheidenes Mass von Genauigkeit werden machen können. Dürften wir ihnen das zugestehen, würden HumboLDTs Angaben ${ }^{6}$ ) für den Anfang unseres Jahrhunderts so ziemlich damit übereinstimmen: „In den schönen Ebenen zwischen San Juan del Rio bis Queretaro bringt 1 Scheffel bisweilen 800 hervor; fruchthare Bodenstrecken geben gemeinhin 3-400. In der Gegend von Valladolid wird eine Ernte, die nur 130 oder 150 Mal das Saatkorn giebt, als schlecht angesehen. Auf unfruchtbarstem Boden zählt man noch 60 oder 80 Körner. Im allgemeinen, glaubt man, kann die Maisproduction in der Äquinoctialgegend des

1) Brasseur de Bourbourg, Histoire des nations civilisées du Mexique, Paris 1857. Bd. 1. S. 115. 2) $\mathrm{Humboldt}$, Essai politique Bd. 3. S. 60. 3) Historia de las Indias cap. 215. 4) Gomara, a. a. O. cap. 208. 5) Hist. gen. Lib. 7 c. 1 : Suele dar una hanega de maiz en sembradura seys, diez, veynte, treynta, cinqüenta, ciento é aun ciento é cinqüenta é mas é menos hanegas, segund la fertilidad é bondad de la tierra, donde se siembra. ${ }^{6}$ ) a. a. O. Bd. 3. S. 55. 
Königreichs Neuspanien als 150fältig geschätzt werden". Einige Jahrzehnte später giebt MÜHLENPFORDT ${ }^{1}$ ) für die Gegenden, wo sich die Felder nur irgend künstlich bewässern lassen, den durchschnittlichen Ertrag des Maises zu 400 für 1 an.

Die Benutzung der Pflanze war, wie noch heute, eine höchst "mannigfaltige. Aus dem Safte des Stengels machte man Zucker und eine Art gegorenen Getränkes. Das sehr zuckerreiche Rohr wird noch heute sehr viel von den Eingeborenen roh gegessen ${ }^{2}$ ). Im trockenen Zustande fanden Stengel und Blätter beim Bau kleiner Häuser und Hütten Verwendung. Noch unreif werden die Kolben gekocht und dienen vielen Armen oft als einzige Nahrung. Aus dem reifen Korn wurde, ähnlich wie bei uns aus der Gerste, eine Art Bier gebraut, welches unter dem Namen chicha in allen Quellen als das allgemeinste Getränk der neuen Welt erwähnt wird. Eigentliches Brot wurde nicht bereitet, sondern nur die von den Spaniern tortillas genannten Kuchen. Zu dem Zweck enthülste man zuerst die Körner, indem man sie in Wasser mit wenig Kalk kochte, bis sie weich geworden, und dann zwischen den Fingern zerdrückte. Darauf wurden sie zwischen Steinen gemahlen, das Mehl mit Wasser zu einem Teig angerührt und zu Kuchen geformt, welche in Öfen gebacken und gleich verzehrt wurden, da sie warm gegessen am schmackhaftesten sein sollen ${ }^{3}$ ). Zuweilen mengte man noch eine Zuthat bei. Die Tortillas der Adligen wurden gewöhnlich aus rotem Mais hergestellt, dem einige Gewürz- oder Arznei-Pflanzen, wie coatzontecoxochitl ${ }^{4}$ ), beigefügt waren, angeblich um den Magen zu erwärmen ${ }^{5}$ ). Die Tortillas, welche die Vornehmen täglich assen, hiessen totanquitlaxcallitlaquelpacholli, d. h. weisse, warme und doppelte Tortillas, oder vietlaxcalli, d. h. grosse

1) Schilderung der Republ. Mexico. Bd. 1. S. 87. 2) Heller, Reisen in Mexico (1845-48), Leipzig 1853. S. 393. $\left.{ }^{3}\right) \mathrm{Ramusio,} \mathrm{Navig.} \mathrm{e}$ viaggi, Venet. 1556. Bd. 3. fol. 306. Oviedo, a. a. O. lib. 7 c. 1. Benzoni, History of the New World, transl. by W. H. Smith, London 1857. S. 84. 4) Die Blume, welche die Schlange tödtet, Brasseur de Bourbourg, a. a. O. Bd. 3. S. 642. 5) Clavigero, a. a. O. Bd. 1. S. 391 . 
Tortillas; die letzteren waren sehr weiss, dünn und weich. Die tlaxcalmimilli genannten waren mehr länglich (fast $1 / 5 \mathrm{~m}$ lang), dick und rundlich. Aus Blätterteig bestanden die köstlich schmeckenden tlacepoallitlaxcalli. Für das gemeine Volk gab es andere zahlreiche Arten Tortillas ${ }^{1}$ ). Die Herstellung dieses von den Spaniern so genannten Brotes und der übrigen Speisen war stets Sache der Frauen. Sie bereiteten es sowohl für ihre Familie, wie für den Verkauf auf dem Markte ${ }^{2}$ ). Das Maismehl gab mit Wasser gekocht eine Art Brei, der den Namen atolli führte. Hernandez unterscheidet 17 sowohl nach Zuthat wie Zubereitungsweise verschiedene Arten des Atolli ${ }^{3}$ ).

Einen ähnlich vielseitigen Nutzen gewährte die Maguey oder Metl (Agave americana). Aus dem Safte wurde wie noch jetzt das gemeinste und beliebteste Getränk der Mejicaner gewonnen, welches sie octli nannten und die Spanier pulque. Nach Clatigero ${ }^{4}$ ) ist das Wort pulque der araucanischen Sprache entlehnt, in welcher es allgemeiner Name für die dort gebräuchlichen Getränke ist; aber es ist schwer zu erraten, wie dieser Name nach Mejico gekommen ist. Die Herstellung des Getränks ist höchst einfach und oft beschrieben worden. Gewöhnlich liefert eine Pflanze 4 Liter den Tag während 4-5 Monaten. Eine sehr kräftige Pflanze vermag in dieser Zeit sogar 1100 Liter zu liefern ${ }^{5}$ ). Die berauschende Kraft des Pulque ist nicht so gross wie die des Traubenweins. Merkwürdig ist es, dass die alten Mejicaner die Trauben ihres einheimischen Weines nicht zur Bereitung eines Getränkes benutzt haben ${ }^{6}$ ). Schon Bernal Diaz ${ }^{7}$ ) berichtet von vielen Weingeländen bei Socochina (wahrscheinlich Xicochinalco de los Totonacos) und ebenso Gomara ${ }^{8}$ ) von denen zwischen Sicuchimatl und Tenhixuacan. Nach Oviedo ${ }^{9}$ ) trugen die wilden Reben gute schwarze Trauben, wovon er selbst gegessen

1) Sahagun, a. a. O. lib. 8 c. $13 .{ }^{2}$ ) Clavigero, a. a. O. S. 391. 3) a. a. O. S. $\left.392 .{ }^{4}\right)$ a. a. O. S. $\left.393 .{ }^{5}\right) \mathrm{Humboldt}$, Essai polit. Bd. 3. S. 157. 6) Gomara, Cronica de la N. Esp. cap. 211. 7) Hist. verdad. cap. $61 .{ }^{8}$ ) a. a. O. cap. $44 .{ }^{9}$ ) Hist. gen. y nat. Lib. 8 c. 24. 
hat, wenigstens hält er sie in Anbetracht ihres Wildwachsens für gut. Auch noch anderwärts wird solcher wilden Trauben Erwähnung gethan, die sehr lange Schösslinge erzeugen und viele Beeren tragen. Die Spanier bereiteten aus ihnen teils Essig, teils ein wenig Wein ${ }^{1}$ ). Der Wein des Landes, d. h. die Pulque, durfte nur mit Erlaubnis der Herren getrunken werden, und diese gestatteten seinen Genuss für gewöhnlich nur den über 50 Jahre alten Personen. Den arbeitenden Klassen war er blos bei der Verrichtung schwerer Arbeiten vergönnt. Für die Krieger war es Ehrenpflicht, sich berauschender Getränke $\mathrm{zu}$ enthalten ${ }^{2}$ ). Bei öffentlichen Hochzeiten und anderen Festlichkeiten durften die Männer über 30 Jahre gewöhnlich 2 Tassen trinken. Die Wöchnerinnen hatten das Recht, in den ersten Tagen davon zu geniessen ${ }^{3}$ ). Die Trunkenheit war also verabscheut. Zur Strafe wurde Männern wie Frauen das Haar kurz geschnitten und ihr Haus niedergerissen, weil der freiwillig des Verstandes sich Beraubende nicht würdig sei, unter Menschen zu wohnen. Die Angabe in dem Berichte eines von CoRTEz' Begleitern, es gälte für eine Ehre, wenn jemand recht viel octli trinken könnte ${ }^{4}$ ), dürfte daher wohl kaum allgemeine Geltung haben. In der Provinz Panuco freilich sollen die Bewohner dem Genuss des Getränkes so ergeben gewesen sein, dass sie, wenn dasselbe nicht mehr durch die Kehle gehen wollte, es sich vermittelst Röhren auf dem Wege beibrachten, auf dem wir unsere Klystiere nehmen ${ }^{5}$ ).

Aus dem Safte gewann man eine Art Honig (mimiahuatl), der zu Zuckerbroten eingetrocknet wurde, wie solche einst dem König Ahuitzotl zum Geschenk dargebracht wurden ${ }^{6}$ ).

1) Ritos antig., sacrif. é idol. de los Ind. de la N. Esp. in den Doc. inéd. para la hist. de España. Bd. 53. S. 517. 2) Torque mada, Mon. Ind. XIV c. 10. Z u rida, Rapp. sur les diff. class. de chefs etc. S. 110. 3) Zurita, a. a. O. S. 110. 4) Ramusio, a. a. O. Bd. 3. fol. 306 b. 5) Diaz, a. a. O. cap. 208 und Ramusio, a. a. O. Bd. 3. fol. 307 b. 6) Tezozomoc, Hist. du Mexique, éd. Ternaux, Paris 1853. cap. 73. In seinem 2. Bericht vom 30. Oktober 1520 sagt Cortez bei der Beschreibung des Marktes von Tenuchtitlan, dass man auf demselben verkaufe miel de abejas y cera y miel de cañas de maiz, que son tan melosas 
Neben dem Saft fanden die Blätter der Agave zu mancherlei Zwecken Verwendung. In ganzem Zustande dienten sie als Material zum Dachdecken. Es wurde aus ihnen sogar in niedrigen Öfen noch ein sehr berauschendes Getränk destilliert ${ }^{1}$ ). Die Fasern gaben das Material für das sog. nequen, welches z. B. in Tlascala in Ermangelung der Baumwolle zu Kleidern verarbeitet wurde ${ }^{2}$ ). Aber auch anderwärts machte man Decken, Schuhwerk und Stricke daraus ${ }^{3}$ ) und aus dem Stengel Körbe. Letzterer diente ausserdem in Zeiten der Not, wo Mais, Cassawi und andere Nahrungsmittel mangelten, als Speise, um den Hunger $\mathrm{zu}$ stillen ${ }^{4}$ ). Aus dem Nequen bestand das Schreibund Zeichenmaterial. CORTEZ bekam ein Stück davon, auf dem die Küste von Panuco bis Tabaseo abgebildet war "). Selbst die Stacheln liess man nicht unbenutzt, sie mussten noch Nadeln abgeben ${ }^{6}$ ).

Die Banane (Musa paradisiaca) kommt nur für die tierra caliente in Betracht, da sie in einer Höhe über $1550 \mathrm{~m}$ vom Meere keine Früchte mehr erzeugt ${ }^{7}$ ). Dafür bringt sie aber in dem heissen Strich überreichen Ertrag. HuмBoLDT ${ }^{8}$ ) hat berechnet, dass ein Stück Land von $100 \square \mathrm{m}$ mehr als $2000 \mathrm{~kg}$ Früchte zu tragen vermag. Ihr Ertrag verhält sich zu dem des Weizens wie $133 \mathrm{zu} 1$ und zu dem der Kartoffel wie $44 \mathrm{zu} 1$.

Dieselbe Region, in welcher die Musa gedeiht, bringt auch die Juca ${ }^{9}$ ) oder quauhcamotli (Jatropha manihot) hervor ${ }^{10}$ ), aus deren Wurzel man das Cassawi genannte Mehl gewann ${ }^{11}$ ). Die Wurzel der Camote oder camotl (Convolvulus batatas) wurde ebenfalls angebaut und gegessen ${ }^{12}$ ), ebenso wie die

y dulces como las de azucar y miel de unas plantas que se llaman en as otras islas maguey, que es muy mejor que arrope; y destas plantas facen azucar y vino, que asimesmo venden.

1) Ramusio, a. a. O. Bd. 3. fol. 306 b. 2) Diaz. a. a. O. cap. 75. 3) Oviedo, a. a. O. Lib. 11. c. 11. 4) Oviedo, a. a. O. Lib. 7 c. 11. 5) Di a z, a. a. O. cap. $102 .{ }^{6}$ ) Gomara, Cronica de la N. Esp. cap. 233. 7) $\mathrm{Humboldt}$, Essai polit. Bd. 1. S. $291 .{ }^{8}$ ) a. a. O. Bd. 3. S. 29. 9) Manihot utilissima; Heller, Reisen in Mexico S. 424. ${ }^{10}$ ) Sahagun, a. a. O. Lib. 8 c. 13 . ${ }^{11}$ ) Benzoni, Hist. of the New World S. 85 und Oviedo, Hist. gen. Lib. 7 c. $2 .{ }^{12}$ ) Sahagun, a. a. O. 
Cacahuate $^{1}$ ) (Arachis hypogaea), deren Samenkörner wie fette Mandeln schmecken und daher so und in Speisen häufig genossen werden ${ }^{2}$ ).

Weit weniger als Nahrungsmittel, sondern hauptsächlich zur leichten Erhaltung von Wassergefässen gab man sich mit dem Pflanzen von Kürbissen $\mathrm{ab}^{3}$ ). Thre Blüten, aioxochquilitl genannt, wurden, nachdem die Schale abgezogen, gekocht und gegessen wie auch ihre Schösslinge. In Oaxaca bildeten sogar die grünen Stengel, mit Maisteig, Salz und grünem Pfeffer zubereitet, die Nahrung der armen Landleute ${ }^{4}$ ).

Auch einige Bohnenarten, wie ayacotli oder yetl (Phaseolus), wurden gebaut ${ }^{5}$ ), doch darüber geben die Quellen $\mathrm{zu}$ wenig Auskunft. Von dem spanischen Pfeffer (Capsicum annuum), mejicanisch chili, zog man verschiedene Arten, deren eine roh gegessen wurde und nicht brannte ${ }^{6}$ ).

Eine beliebte Nahrung gab die cacavatl, die Frucht des Baumes cacahuaquahuitl (Theobroma cacao) ab, die in verschiedener Zubereitung genossen wurde. Dass sie grün als Nahrung diente ${ }^{7}$ ), wo dann die Oberhaut einen guten Geschmack haben soll ${ }^{8}$ ) und die Bohnen noch saftig sind, war wohl der seltenere Fall. Aus den reifen Bohnen bereiteten die Mejicaner eines ihrer alltäglichen Getränke, die Chocolate (chocolatl) ${ }^{9}$ ). Es bestand aus Cacaomehl und Wasser, dem bisweilen Honig zugethan wurde $\left.{ }^{10}\right)$. Auf Montezumas Hoftafel fehlten nie die Krüge mit diesem Getränk, auf denen noch der Schaum stand ${ }^{11}$ ). Überhaupt machte es das gewöhnliche Getränk der Adligen und Krieger aus, bei denen es Ehrenpflicht war, keine berauschenden Getränke zu geniessen ${ }^{\mathbf{1 2}}$ ). Die Vornehmen tranken

1) Tlalcacahuatl bei Sahagun, a. a. O. lib. 11 (Catalog der Pflanzen). 2) Heller, a. a. O. S. $\left.430 .{ }^{3}\right)$ Oviedo, a. a. O. lib. 7 c. $\left.8 .{ }^{4}\right) \mathrm{Sahagun}$, a. a. O. lib. XI c. 7 \$. 5) Sahagun, a. a. O. XI (Pflanzencatalog). 6) Oviedo, a. a. O. Lib. 7 c. $\left.7 .{ }^{7}\right)$ Ritos antig., sacrif. é idol. in den Doc. inéd. para la hist de Esp. Bd. 53. S. 518. ${ }^{8}$ ) Torque mada, Mon. Ind. XIV c. 42 . 9) Brasseur de Bourbourg, Hist. des nat. civil. Bd. 3. S. 643: Chocolatl, composé de choca gémir ou pleurer et de atl eau; c'est-à-dire l'Eau qui gémit, à cause du murmure que fait le moulinet en le tournant. ${ }^{10}$ ) Gomara, Cronica cap. 211. 11) Diaz, a. a. O. cap. 91. 12) Torquemada, a. a. O. XIV c. 10. 
den Cacao "mit Honig, mit Vanille (tlilxochitl), rot, orange, schwarz und weiss. Die verschiedene Färbung rührte weniger von den verschiedenen Arten Bohnen her, als vielmehr von dem Grade des Röstens. Man trank ihn aus reich verzierten und bemalten Tassen ${ }^{1}$ ). Ursprünglich wurde die Chocolate kalt genossen; als warmes Getränk ist sie erst in der zweiten Hälfte des 16. Jahrhunderts aufgekommen ${ }^{2}$ ). Über ihren Geschmack und ihre Wirkung äussern sich die alten Chronisten in auffallend verschiedener Weise. Einmal soll sie dem nicht daran Gewöhnten Ekel verursachen ${ }^{3}$ ) und ein für Schweine geeigneteres Getränk als für Menschen sein ${ }^{4}$, das andere Mal soll sie besser bei warmer als bei kalter Witterung bekommen ${ }^{5}$ ), dann soll die Bohne trocken genossen schaden, besonders wenn es fortgesetzt des Abends geschieht ${ }^{6}$ ), und schliesslich soll sie zu einem Teige verarbeitet bei Katarrh, Brust- und Magenleiden lindernd wirken ${ }^{7}$ ). Der Verbrauch der Bohnen muss ein ganz bedeutender gewesen sein, denn grosse Mengen wurden in kleinen und grossen Töpfen auf dem Markte feilgehalten ${ }^{8}$ ). Zur Bereitung der Chocolate verwendete man die kleinste Sorte, das tlalcahuatl; die anderen geringeren Arten dienten nur als Münze ${ }^{9}$ ). Der letztere Gebrauch war in ganz Mittelamerika üblich $\left.{ }^{10}\right)$. Man zählte den Cacao nach xiquipilli (zu

1) Sahagun, a. a. O. lib. 8 c. 13. 2) Torquemada, a. a. O. XIV c. 14 und $\left.42 .{ }^{3}\right)$ A costa, Hist. nat. y moral de las Indias, Sevilla 1590. Lib. IV c. 22. ${ }^{4}$ ) Benzoni, Hist. of the New World S. 150. 5) Ramusio, a. a. O. Bd. 3. fol. 306. 6) Torquemada, a. a. O. XIV c. 42. ${ }^{7}$ Acosta, a. a. O. 8) Torquemada, a. a. O. XIV c. 14. 9) Clavigero, a. a. O. Bd. 1. S. 23 und Bd. 2. S. 350. $\left.{ }^{10}\right)$ Diaz, a. a. O. cap. 92 ; Benzoni, a. a. O. S. 149; Gomara, Cronica cap. 78 und Historia cap. 206; Acosta, a. a. O. IV c. 22; Torquemada, a. a. O. XIV c. 42 ; Oviedo, Hist. gen. Lib. 8 c. 30 . Wo der Cacao nicht mehr gedieh, dienten andere Producte als Tauschmittel, so in Meztitlan baumwollene Tücher: casi corrian por moneda unas mantillas pequeñas, de cinco á seis palmos de largo y tres de piernas, y esta contratacion se hacia en los mercados para lo necessario y sustento ordinario, y fuera desto, ni se compraban ni se vendian casas ni tierras, ni se hacia contrato de otra presea alguna; carecian, y aun hoy dia no usan, del cacao, que en esta Nueva España corre por moneda y por comida y bebida (Relacion de la prov. de Meztitlan in den Doc. inéd. de Indias Bd. 4. S. 551). 
8000 Bohnen) und nach Säcken zu 3 xiquipilli oder 24000 Bohnen. Die Bohne hatte zur Zeit, als die Spanier ins Land kamen, etwa $1 / 2$ Maravedi an Wert $^{1}$ ). Etwa ein halbes Jahrhundert später galten 80-100 Bohnen 1 Real oder, da sie nach cargas (zu 3 xiquipilli) verkauft wurden, die carga $30-28$ Pesos zu 8 Reales ${ }^{2}$ ). Am Ort der Ernte soll die carga mit 5-6 Goldpesos bezahlt worden sein ${ }^{3}$ ). In der Provinz Nicaragua galt zu Oviedos Zeit ein Kaninchen (conejo) 10 Bohnen und ein Sklave $100^{4}$ ). Heute sind 200 Bohnen gleich 1 Real, also etwa 50 Pfennig ${ }^{5}$ ).

Von narkotischen Genussmitteln besassen die Mejicaner nur den Tabak und zwar kultivierten sie davon zwei Arten, die sich in der Grösse der Pflanze und der Blätter unterschieden. Die kleinere Art, welche die gemeinere war, hiess picietl (Nicotiana tabaccum). Man verwendete das Blatt zum Rauchen, zu Pflastern und als Pulver zum Schnupfen ${ }^{6}$ ). Beim Rauchen wurde es zusammen mit wohlriechenden Kräutern und Harzen, wie xochiocotzotl (Liquidambar styraciflua), in eine (poquietl genannte) Röhre aus Rohr, Holz oder Silber gelegt und nach dem Anzünden der Rauch mit dem Munde eingezogen ${ }^{7}$ ). Namentlich von den Vornehmen wurde zum Zwecke der Einschläferung nach dem Frühstück und Mittagsmahl stets eine Quantität Tabak geraucht ${ }^{8}$ ). ANTONIO DE SoLIs ${ }^{9}$ ), der erst über anderthalb Jahrhunderte nach der Eroberung schrieb und auf den wir uns wenig verlassen können, will wissen, dass sie das Rauchen Medicin nannten und der Saft

1) Ramusio, a. a. O. Bd. 3. fol. 306. Der Goldpeso oder Castellano hatte 450 Maravedis, sein Wert würde heutzutage 40 Francs betragen; s. Don Alvaro Reynoso, Agricultura de los Indígenas de Cuba y Haití, Paris 1881. S. 87. 2) Suarez de Peralta, Tratado S. 166. 3) Ritos ant., sacrif. é idol. etc. in den Doc. inéd. para la hist. de España Bd. 53. S. 518. 4) Oviedo, a. a. O. Lib. 8 c. 30 . 5) San Salvador und Honduras. Amtlicher Bericht des Lic. Dr. Diego Garcia de Palacio, 1576. Übers. von Dr. A. v. Frantzius, Berlin 1873. S. 14. 6) Sahagun, a. a. O. Lib. 4 c. $\left.37 .{ }^{7}\right)$ Suarez de Peralta, a. a. O. S. 10. 8) Diaz, a. a. O. cap. 91. 9) Historia de la conquista de Mexico, Madrid 1783. Lib. III cap. 15 . 
der Pflanze eines von den Ingredienzien gewesen ist, wodurch sich die Priester besinnungslos gemacht hätten, wenn sie mit ihrer Gottheit sich verständigen wollten. Auch als eine Art Weihrauch scheint man den Tabak benutzt zu haben. Als nach siegreich beendetem Krieg das aztekische Heer einst in die Hauptstadt zurückkehrte, zogen ihm die Behörden der Stadt entgegen und die Greise trugen Pfannen, auf denen sie picietl verbrannten, um den Feldherren Weihrauch zu streuen ${ }^{1}$ ).

Das Bekleidungsmaterial lieferte die Baumwolle (Gossypium album). Sie wurde in beträchtlicher Menge gezogen und ein schwunghafter Handel mit ihr nach den Gegenden getrieben, welche dieselbe nicht gedeihen liessen. So erzeugte Tlascala, weil zu kalt, die Pflanze nicht, weshalb sich die Bewohner für die Bekleidung zum Teil mit Metl-Blättern behalfen. Die Baumwolle bezogen sie aus dem Reiche Montezumas ebenso wie das Salz, so dass sie dadurch in gewissem Grade von ihm abhängig waren ${ }^{2}$ ). Die Frauen, welche eine ausnehmende Geschicklichkeit im Weben und Sticken besassen, verfertigten aus der Baumwolle eine Menge der feinsten, oft mit Federn durchwirkten Stoffe. Die zum gewöhnlichen Gebrauch dienenden Zeuge kamen meist aus den Ortschaften der Küstenprovinz Costatan, unfern von Veracruz ${ }^{3}$ ).

Alle erwähnten Naturprodukte wurden auf den Märkten in den grösseren Städten des Landes feilgehalten. Besonders grossartig war das Treiben auf dem grossen Marktplatz in Tenochtitlan. CORTEZ und seine Gefährten staunten nicht wenig beim Anblick der Menschenmenge, die sich auf dem Platze bewegte, und der vielen Waren, welche zum Verkauf ausgestellt waren. Jeder Warengattung war ein bestimmter Aufstellungsort angewiesen ${ }^{4}$ ). Trotz der vielen täglich auf dem Platze zusammenkommenden Menschen herrschte die grösste Ordnung. Auf dem Markte waren stets drei Richter

1) Tezozomoc, Hist. du Mexique, Paris 1853, cap.32. 2) Gomara, Cronica de la N. Esp. cap. 53. 3) Diaz, a. a. O. cap. 91. 4) Diaz, a. a. O. cap. 92. Die $\mathrm{Zahl}$ von 20-30000 Personen, welche täglich auf dem Markte gewesen sein sollen, wird natürlich ganz willkürlich sein. 
nebst Gerichtsvollziehern anwesend, welche Warenschau abhielten und sich von der Richtigkeit der beim Verkauf gebrauchten Masse überzeugten ${ }^{1}$ ).

\section{IV.}

\section{Zuchttiere.}

Von Säugetieren wurde nur ein kleiner einheimischer Hund aufgezogen. Man scheint 4 Arten gehabt zu haben, wenigstens führt $\mathrm{SAHAGUN}^{2}$ ) vier verschiedene Namen für sie auf: chichi, itzcuintli, xochiocoiotl und tetlamin oder tevitzotl. Der chichi oder techichi wurde verschnitten, gemästet und sein Fleisch auf dem Markte verkauft ${ }^{3}$ ). Besonders schmackhaft soll dass Fleisch der tlalchichi genannten Art gewesen sein. Die Spanier machten der Rasse den Garaus ${ }^{4}$ ).

Zum grössten Teil indessen lieferte die Vogelwelt die Fleischnahrung. Der Truthahn (totolin oder huexolotl) ${ }^{5}$ ) muss in bedeutender Menge gehalten worden sein, wenn auch die Angaben der Chronisten übertrieben sein mögen. In seinem Berichte an den Kaiser giebt ConTez die Zahl der auf Montezumas Besitzungen gehaltenen auf mehrere Tausende an. Auf den Märkten wurde täglich eine bedeutende Anzahl verkauft ${ }^{6}$ ). Unter den von den Chronisten erwähnten Gänsen und Enten sind wohl wilde $\mathrm{zu}$ verstehen. BernaL Diaz ${ }^{7}$ ) freilich spricht von zahmen Enten, denen von Zeit zu Zeit die Federn ausgerupft wurden, die einen bedeutenden Handelsartikel abgaben. Jedenfalls dürfen wir uns von der Züchtung des Truthahns nicht einen zu hohen Begriff machen; er hat gewiss nicht die Pflege erhalten, die ihm heute zu Teil wird.

Ebenso ist es wohl mit der Zucht der Bienen gewesen, die besonders von den Indianern der Provinz Xalisco betrieben

1) Diaz, a. a. O. und Cortez, Cartas al emperador bei Barcia, Histor. primit. ${ }^{2}$ ) Hist. gen. de 1. cos. de N. Esp. Lib. XI c. 1 §. 3) Gomara, Cronica cap. 79 und Sahagun, a. a. O. 4) Sahagun, a. a. O. 5) Sahagun, a. a. O. Lib. XI c. $2 \S 9$, nennt die Henne totolli und den Hahn vexolotl. Bei Tezozomoc, Hist. de Mexique, cap. 55 heisst der Hahn ebenso, er schreibt aber huexolotl. ${ }^{6}$ ) Torquemada, a. a. O. XIV c. $14 .{ }^{7}$ ) a. a. O. cap. 91. 
wurde ${ }^{1}$ ). Die einheimischen Bienen sind klein und ohne Stachel, weshalb ihnen die Spanier den Namen angelitos gegeben haben ${ }^{2}$ ). Ihr Wachs wurde ebenso wenig wie Talg oder Ö1 zur Beleuchtung verwendet. Gewöhnlich nahm man Holzspähne oder Cactusstengel, die zwar genügend Licht und guten Geruch gaben, aber durch ihren Rauch die Wohnungen zu sehr schwärzten. Indessen bedurften sie der Beleuchtung auch gar nicht so sehr, da sie ihre gesamte Arbeit am Tage verrichten konnten und daher während der Nachtstunden ausruhten.

Bei der Cochenille (nochitzli) ${ }^{3}$ ) kann man eher von einer Zucht sprechen ${ }^{4}$ ). Sie ist sehr alt in Mejico. HerReras Angabe ${ }^{5}$ ), die Eingeborenen hätten die Cochenille zwar besessen, aber keinen Gebrauch davon gemacht, ist für die Kulturvölker Mejicos sicher unzutreffend. Am blühendsten war die Zucht in Mixteca und hier machte sie den bedeutendsten Handelszweig aus. Im 16. Jahrhundert wurde sie auch in Tlascala und anderen Orten gezogen, wo dann ebenfalls ein lebhafter Handel damit emporkam ${ }^{6}$ ).

1) Oviedo, Hist. gen. y nat. Lib. 34 c. $\left.2 .{ }^{2}\right) \mathrm{Humboldt}$, Essai politique Bd. 3. S. $\left.240 .{ }^{3}\right)$ Nach $\mathrm{Sahagun}$, a. a. O. Lib. XI c. $11 \S 1$, heisst nochetzli das Blut der Tunas, weil die Insekten auf einer Art derselben leben. Nur die Farbe mit der man Scharlach färbte, scheint also nochetzli bedeutet zu haben. 4) A costa, Hist. nat. y mor. IV c. 23: Ay otros tunales, que aunque no dan fruto, los estiman mucho mas, y los cultivan con gran cuydado, porque aunque no dan fruta de tunas, dan empero el beneficio de la Grana. Porque en las hojas deste arbol, quando es bien cultivado, nacen unos gusanillos pegados a ella, y cubiertos de cierta telilla delgada: los quales delicadamente cogen, y son la Cochinilla tan afamada de Indias, con que tiñen la grana fina: dexanlos secar, y assi secos los traen a España, que es una rica y gruessa mercaderia: vale la arroba desta Cochinilla, o Grana muchos ducados. En la flota del año de ochenta y siete vinieron cinco mil y seyscientas y setenta y siete arrobas de Grana, que montaron dozientos y ochenta y tres mil y setecientos y cincuenta pesos, y de ordinario viene cada año semejante riqueza. Danse estos Tunales en tierras templadas, que declinan a frio: en el Piru no se han dado hasta agora: y en España aunque he visto alguna planta destas, pero no desuerte que aya que hazer caso della. 5) Hist. gen. de las Ind. Dec. IV lib. 8 c. $8 .{ }^{6}$ ) Clavigero, a. a. 0 . Bd. 1. S. 69 . 
Obwohl nicht hierher gehörig, will ich doch der Merkwürdigkeit wegen noch zweier animalischer Nahrungsmittel Erwähnung thun. Das waren geröstete Ameisen ${ }^{1}$ ) und die schmackhaften Eier der Corixa mercenaria ${ }^{2}$ ). Nach der Schilderung der alten Chronisten lagen die letzteren wie eine schwammige, käseartige Substanz auf der Oberfläche der Seeen um Tenochtitlan. Zu gewisser Zeit des Jahres sammelten sie die Umwohner wit feinen Netzen, trockneten sie und machten Brote daraus, die sie als Käse assen und äusserst schmackhaft fanden ${ }^{3}$ ). Fis wurde davon nicht nur eine grosse Menge auf dem Markte verkauft, sondern auch weit forttransportiert ${ }^{4}$ ). Einmal nahmen die Spanier bei der Belagerung Tenochtitlans ein Fahrzeug weg, dessen Ladung ganz aus dem käseartigen Schlamm bestand ${ }^{5}$ ). Vielleicht hatte man zur Zeit einer Hungersnot nach dem schlechten Nahrungsnittel gegriffen und sich dann daran gewöhnt. Noch НumboLdT ${ }^{6}$ ) sah die Eier auf dem Markt in Mejico verkaufen; sie hiessen aguautle und wurden an der Oberfläche des Sees von Tezcuco gefischt. Auch TYLOR ${ }^{7}$ ) erwähnt ihrer noch. Oft soll die Masse so viele Vögel angezogen haben, dass bisweilen zur Winterzeit die Seeen stellenweise von ihnen bedeckt waren ${ }^{8}$ ).

Als die Spanier in das Land kamen, gab es in Mejico weder Zug- noch Lasttiere. Dadurch wurden natürlich die Leistungen im Ackerbau und der Verkehr ungemein beschränkt.

1) Sahagun, a. a. O. Lib. XI c. $5 \$ 9$ : Hay hormigas que se crian en tierras frias; son pequeñuelas, negras, muerden y sus huesos son blancos, en algunas partes las comen, y por eso las llaman azcamolli. Die Vornehmen assen auch ein Ragout von unas hormigas aludas con chiltecpitl (gusano colorado), ausserdem assen sie unos gusanos que son del maguey con chiltecpitlmolli, Sahagun, a. a. O. Lib. VIII c. 13. 2) Torquemada, a. a. O. XIV c. 14. Peschel, Völkerkunde, 5. Aufl. von A. Kirchhoff, Leipzig 1881. S. 443. ${ }^{3}$ ). Diaz, a. a. O. cap. 92 und Gomara, Cronica cap. 78, 79. 4) Herrera, a. a. O. Dec. II lib. 7 c. 16. 5) $\mathrm{Diaz}$, a. a. O. cap. 153. 6) Reise in die Äquinoctialgegenden des neuen Continents. Deutsch bearbeitet von H. Ha uff, Stuttgart 1861. Bd. 6 . S. 261. ${ }^{7}$ ) Anahuac or Mexico and the Mexicans etc. S. 156: Sie rühren von Corixa femorata und Notonecta unifasciata her. $\left.{ }^{8}\right) \mathrm{Herrera}$, a. a. O. Dec. II lib. 7 c. 16 . 
Alles, was nicht zu Wasser fortgeschafft werden konnte, musste der Mensch sich aufladen. Allmählich hatte sich eine besondere Klasse der Lastträger ausgebildet, die tlamama oder tlameme. Die gewöhnliche Belastung derselben betrug ungefähr 60 Pfund $^{1}$ ) und die Tagereise, die sie machten, 15 Millas ${ }^{2}$ ). Die Last, welche gewöhnlich in Mais, Baumwolle und anderen Handelswaren bestand, trugen sie in sog. petlacalli. Es waren Kästen von Rohr mit einem Fellüberzug; dadurch blieben sie leicht und schützten zugleich den Inhalt gegen Sonne und Regen $\left.{ }^{3}\right)$. Nicht recht übereinstimmend hiermit ist der Bericht ZuRiTaS ${ }^{4}$ ). Als er die Ursachen der Verminderung der Bevölkerung seit Ankunft der Spanier bespricht, führt er den Umstand an, dass die Spanier die Indianer zu Tausenden gezwungen hätten, enorme Lasten von Waren mehrere Tagereisen zu tragen und dabei von warmen in kalte Gegenden zu gehen, was für sie, als nicht daran gewöhnt, todbringend wäre. Wie dem aber auch sein möge, das Fehlen jeglicher grösseren Haustiere muss den Aufschwung von Ackerbau, Handel und Verkehr bedeutend beeinträchtigt haben.

1) Gomara, Cronica cap. 8 und 43. Suarez de Peralta, Tratado etc. S. 21, giebt als Gewicht, welches die Eingeborenen zu tragen im Stande sind, media fanega de maiz an. Nach der Eroberung durften sie mit nicht mehr als 50 Pfund belastet werden: En el Cabildo que se tuuo á los 30 de Enero de 1542 dize el Secretario, que ninguna persona de qualquier calidad que sea, no sea ossado á cargar, ni cargue tameme ninguno mas de dos arrobas de carga, so pena que el que lo contrario hiziere, pierda lo que assi llevare en el dicho tameme o tamemes, hallandole en las tales carga ó cargas, mas pesso de dos arrobas (Remesal, Historia de la prov. de Chiapa y Guatemala, Madrid 1619. Lib. 7 cap. 2). 2) Clavigero, a. a. O. Bd. 1. S. 352. 3) Clavigero, a. a. O. ${ }^{4}$ ) Rapport sur les diff. classes de chefs etc. S. 280 . 


\section{I T A.}

Natus sum, Maximilianus Alexander Steffen, die XVIII. mens. Dee. a. h. s. LX. in vico Marchico, eui nomen GrossNeuendorf inditum est, patre Ferdinando, matre Mathilda e gente Oesterling, praematura morte mihi ereptis. Fidei addietus sum evangelicae. Litterarum elementis imbutus Berolini per tres annos gymnasium Colonicum et per sex annos scholam realem Koenigstaedtianam frequentavi. Maturitatis testimonium adeptus ineunte vere a. h. s. LXXIX. universitatis Berolinensis philosophorum ordini adscriptus in studium linguarum recentium et geographiae incumbere coepi scholisque interfui prof. doct. Bresslau, Gaspary, Geiger, Kiepert, Lepsius, Schrader, Tobler, Zeller, Zimmer, Zupitza. Duo vero semestria Berolini versatus studia ibi incepta in universitate Halensi persecutus sum et per duos annos et sex menses scholas audivi virorum illustrissimorum: Aue, Cornelius, Credner, Dïmmler, Elze, v. Fritsch, Herbst, Keil, Kirchhoff, Lehmann, Suchier, Ulrici, Zacher. Benevolentia Alfredi Kirchhoff et Hermanni Suchier mihi contigit ut seminarii geographici et romanici per tria semestria essem sodalis.

Viris illis quos nominavi cum omnibus tum maxime $A$. Kirchhoff et H. Suchier gratias quam maximas et nune ago et semper habebo. 


\section{TH E S EN.}

I.

Die Südseeinseln sind stets Inseln gewesen.

II.

Die Glaubwürdigkeit des Inca Garcilasso de la Vega (Comentarios Reales que tratan del origen de los Incas etc.) wird mit Unrecht in Zweifel gezogen.

\section{III.}

Die Behauptung, dass man die Bindung nasaler Vokale mit oralen im Altfranzösischen vermieden hätte, ist unbegründet. 